\title{
Airborne diseases: Tuberculosis in the Union Army
}

\author{
Javier A. Birchenall * \\ Department of Economics, 2127 North Hall, University of California, Santa Barbara CA 93106, United States
}

\section{A R T I C L E I N F O}

\section{Article history:}

Received 6 May 2009

Available online 12 February 2011

\section{Keywords:}

Mortality

Tuberculosis

Union Army

\begin{abstract}
A B S T R A C T
This paper examines the medical histories of a sample of 25,000 Union Army soldiers and veterans to study the determinants of diagnosis, discharge, and mortality from tuberculosis. We find that water and airborne diseases during the war contributed significantly to the presence of tuberculosis. Height and a higher body mass index (BMI) are also associated with protection against TB but these effects are not always robust. As an upper bound, we estimate that the contribution of modern gains in height and in BMI to the mortality decline of tuberculosis ranges from one-fourth to one-half with the rest explained by the decline in the prevalence of water and airborne diseases, especially diarrhea, dysentery, and typhoid played. The paper finds weaker support for alternative hypotheses that rely on occupational influences and exogenous changes in the virulence of tuberculosis.
\end{abstract}

(c) 2011 Elsevier Inc. All rights reserved.

\section{Introduction}

Tuberculosis, one of the oldest and deadliest recognized diseases in humans, had a prominent role in the secular decline in mortality of northwestern Europe and North America. According to McKeown (1977, Table 3.1), airborne infectious diseases contributed to $40 \%$ of the decline in death rates in England and Wales between 1851 and 1971, with tuberculosis representing $17.5 \%$ of the overall decline. The alternative decomposition in Woods (2000, Table 8.7), which attributes 35\% of the decline in death rates in England and Wales between 1861 and 1891 to tuberculosis, gives a slightly lower figure for tuberculosis, but it is nonetheless consistent with its prominence over other individual causes of death. Between 1871 and 1951, England and Wales gained 27 years of life expectancy at birth. Of the 27 years gained, tuberculosis represents about a $40 \%$ contribution or a 12 -year gain, (Caselli, 1991).

Perhaps not surprisingly, there have been multiple explanations proposed to account for the decline in the prevalence and fatality of tuberculosis. Some of these explanations include improvements in diets (or their quality), innovations in public health and living conditions, and an exogenous decline in the virulence of the pathogen responsible for the disease. ${ }^{1}$ While the previous explanations are appealing, and each has found some empirical support, a comprehensive analysis that considers several of these potential factors simultaneously is not available. Thus, previous analyses have focused on one or another particular explanation but have not yet given full consideration to multiple aspects at the same time. The goal of this paper is to shed light upon the many determinants of adult morbidity and mortality from tuberculosis in historical populations using individual information, socioeconomic characteristics, and military and medical records of approximately 25,000 Union Army soldiers during the American Civil War.

\footnotetext{
* Fax: +1 8058935275 .

E-mail address: jabirche@econ.ucsb.edu.

1 McKeown's (1977) famous accounting for the role of nutrition in the mortality decline attributed the entire decline in tuberculosis to changes in diets. Preston and Van de Walle (1978) showed that sanitation improvements in cities were also an important factor in the declining trends in tuberculosis. Similarly, Mercer (1990) has suggested that TB, as a sequel to smallpox infections, declined due to the vaccination against smallpox initiated in the eighteenth century. Separately, Bryder (1988) argued that improvements in housing and working conditions reduced long-term exposure to infected agents and predisposition to TB. Woods and Shelton (1997) and Woods (2000) proposed yet an additional and alternative explanation: "The simplest explanation is that the disease became less virulent and that this was the principal reason for a reduction in the risk of the disease developing and leading to early death," Woods (2000, 340).
} 
This exercise advances the literature is many ways. First, we try to isolate the role of different factors in the prevalence and mortality from tuberculosis and relate them to some of the explanations just noted. Thus, we provide what appears to be the first comprehensive analysis of tuberculosis in historical populations. Second, we examine individual information whereas most of the existing literature relies on aggregate mortality statistics, (see, e.g., McKeown, 1977; Preston and Van de Walle, 1978). Individual data allows us to control for many different influences using an econometric duration analysis. Finally, the Union Army sample is composed of a large number of individuals brought together from many different backgrounds. This diversity is especially useful to identify risk factors in tuberculosis.

The central findings of the paper are the following. We find that disease experiences during the war are associated with higher risks of developing tuberculosis. This is particularly the case for waterborne conditions such as diarrhea and typhoid, but is also true for respiratory infections such as pneumonia and bronchitis. These effects are statistically robust across many specifications. We also find that increases in height, a measure of long-term nutritional status, and in the body mass index BMI, a measure of current nutritional status, are associated with a reduced risk of tuberculosis. An increase in height lowers the risk of diagnosis and discharge but the statistical significance varies across the robustness checks. An increase in BMI lowers mortality rates even after multiple controls for disease experiences are included and even after one controls for the diagnosis of tuberculosis. Further, gunshot wounds during the war are associated with higher risks of tuberculosis, but an increase in the number of battles prior to diagnosis provided a 'protective' effect against the disease. (We will return to possible explanations based on selection for this finding later on.) Occupation at enlistment had no predictive power for diagnosis or discharge, and those who enlisted in cities with small populations (one of our proxies for disease experiences in early life) had a relatively smaller risk probably related to the different degrees of exposure to disease prior to enlistment.

The effects just listed, even when statistically significant, only amount to a small reduction in the risk of diagnosis. To measure the relative influence of height and disease influences in the mortality decline from tuberculosis, we estimate the change in the risk if the average Union Army soldier had the average height of the current U.S. male population and if diarrhea or other conditions prior to tuberculosis are fully eradicated. As just noted, the total decline in risk is small but the decomposition suggests that about one-fourth to one-half of the predictable decline in tuberculosis can be associated to the observed increase in height with the remaining fraction due to the elimination of the other diseases, especially diarrhea. For reasons we will describe in detail later on, we interpret the measured contribution of these nutritional variables as an upper bound for their influence in tuberculosis.

Separately, the large effect of water and airborne diseases in the prevalence of tuberculosis confirms the synergistic relationship between different infectious diseases stressed by Preston and Van de Walle (1978), Fogel (1997), and Scrimshaw and SanGiovanni (1997) among many others. The findings also suggest that explanations based on an exogenous decline in the virulence of the infective organism that causes TB are not an exclusive factor behind the changes in tuberculosis. (Exogenous changes in the pathogen also fail to account for the persistent infectivity of tuberculosis in less developed countries as well as the recent recrudescence of the disease in developed countries after 1980.)

Finally, in terms of the nutrition-public health debate, our findings indicate that nutritional change should be regarded as an important factor in the secular decline in tuberculosis mortality but that its importance is not exclusively a consequence of changes in diets. While a separation between diets and disease is not precise or informative, the disease component of nutritional status seems more important (or at least as important) as the "pure" dietary component.

Our findings provide important insights for the long-standing nutrition-public health debate. McKeown (1977) examined aggregate cause-specific mortality statistics in the UK and correctly pointed out that reductions in tuberculosis mortality began long before the tubercle bacillus was identified by Koch in 1882, and prior to any medical innovation in the treatment of tuberculosis. He also considered improvements in living standards as the only potential explanation for such a decline. In order to see the basis for McKeown's (1977) account, Fig. 1 presents information from a sample of countries between 1911 and 1938 . The figure reveals the decreasing trend in developed countries and the disruptions due to World War I. ${ }^{2}$ Aside from the outbreaks experienced during both world wars, mortality from TB declined gradually through most of the twentieth century in the U.S. and in Europe. $^{3}$

The accounting provided by McKeown (1977), however, is flawed as malnutrition is the outcome of diets but also of energy claims due to disease and physical exertion, (see, e.g., Preston and Van de Walle, 1978; Fogel, 1997). One measure that encompasses both of these aspects is height. Height varies with socioeconomic conditions, essentially with conditions in early life, and there is a health gradient correlated with stature, (Fogel, 1997). Since height gave some protection against TB, it would be interesting to determine the source of the differences in height in our data. Unfortunately, the cause of the variations in nutrition at early ages in the Union Army sample is difficult to determine. It seems that height varied mainly with differentials in environmental conditions and somewhat less importantly with diets (see Haines et al., 2003). Still, to provide a sense of the bias in McKeown (1977), notice that even after attributing all differences in height to differences in diets, improvements in diets cannot

\footnotetext{
2 Dubos and Dubos (1953) present evidence of increasing mortality from tuberculosis during the world wars especially for the Netherlands, Denmark, and Belgium. Between 1913 and 1917, death rates from respiratory tuberculosis increased approximately $17 \%$ (35\% for the period of $1913-1918$, which includes the influenza pandemic) in England and Wales, Bryder (1988, 109). Bryder (1988, chap. 4) also documents the adverse effects of inadequate nutrition during the war and its associated recessions in Great Britain, Germany, and Denmark.

${ }^{3}$ Fig. 1 also indicates that mortality rates in the U.S. and Japan remained relatively unaffected by the war, compared to Italy, and England and Wales. Death rates in Japan were higher than in New Zealand, the U.S., and European countries, but the highest death rates were observed in Chile, the least developed country in the sample. Chile's tuberculosis mortality rates were trendless and only started to decline after World War II (Lowell, 1969).
} 


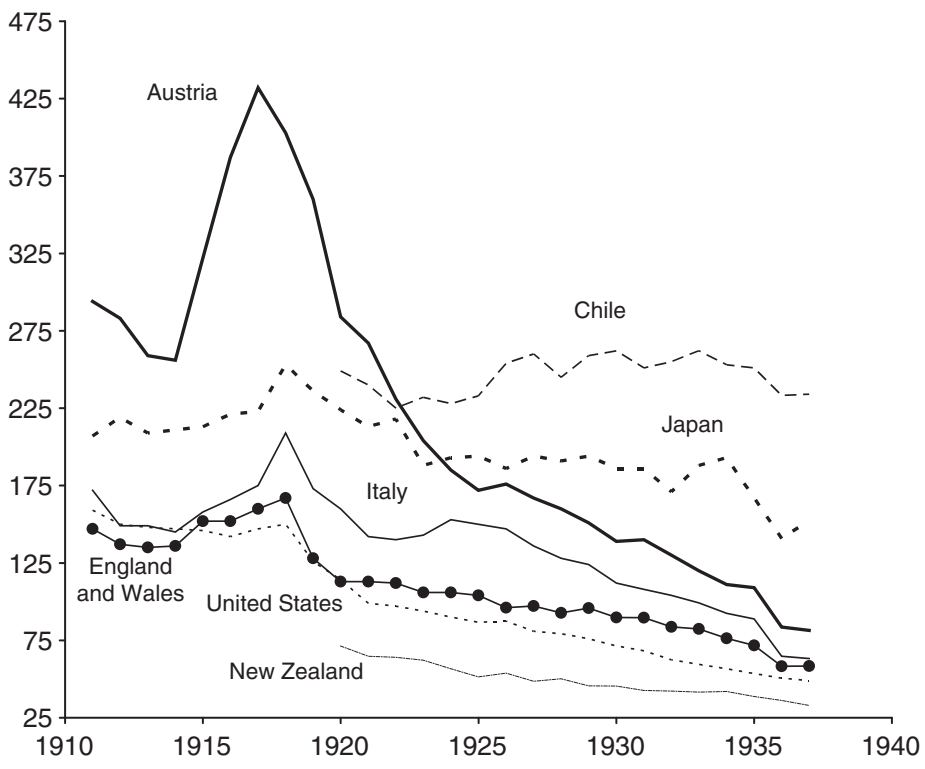

Fig. 1. Mortality rates from tuberculosis (per 100,000), selected countries. Data from Wolff (1940).

be considered responsible for more than one-fourth to one-half of the decline in tuberculosis. In this sense, the findings presented here provide an upper bound for the influence of "pure" improvements in nutritional status.

Studying tuberculosis prior to the advances of modern medicine helps avoid many of the difficulties associated with the treatment of therapies against the disease but faces other statistical problems such as measurement errors and selection biases. We will discuss these concerns in detail later on using evidence from the medical histories during the war and different samples in the population. For example, notice that the extent of tuberculosis diagnosis depended on the conditions of the war because a large requirement of soldiers lowered the probability of seeking a doctor and hence of being diagnosed. The selective nature of diagnosis helps explain why battles provided a protective effect as they reduced the probability of being examined by a doctor and hence of being diagnosed. In addition to diagnosis, we study discharge patterns due to tuberculosis. But, unfortunately, there is no effective measure to deal with the fact that diagnosis of tuberculosis (and of other diseases) was more likely to occur in unhealthy individuals. In other words, seeking medical assistance for soldiers was not an exogenous event.

To mitigate the influence of non-random selection into diagnosis, we examine tuberculosis mortality for a sample of veterans who received pensions after 1890 . After 1890, measurement problems are mitigated as tuberculin tests became available in 1892 . Further, pensions were granted on the grounds of service in the Union Army and not by wounds received during the war, as it had been the case before 1890. As the pensions awarded were non-trivial economic amounts, the liberalization in the conditions needed for pensions serves to identify the effect of health conditions on mortality from tuberculosis in a sample of Civil War veterans who will seek doctors not because their health deteriorated drastically (as is arguably the case during the war), but because of the promise of a pension. In our analysis of mortality, the effect of height is negative but not statistically different from zero but the veteran's initial BMI is statistically as well as economically significant.

There are many related literatures, some of which were mentioned before. One particular strand of the literature, (see, e.g., Preston and Van de Walle, 1978), has emphasized the synergistic nature of diseases in tuberculosis mortality. They have shown that a decline in waterborne diseases due to improvements in public sanitation lowered TB mortality. We provide further support to this literature but our analysis does not rely on aggregate mortality statistics which are the sources employed by Preston and Van de Walle (1978). In addition, the paper complements studies that estimate the effect of disease exposure and socioeconomic factors in wartime, mid-life, and old age mortality in the US using individual data. For example, according to Costa (2003), infectious respiratory diseases contracted while in the Union Army were particularly harmful for old age mortality. Lee (1997) also identified important socioeconomic factors in the disease and mortality experience of Union Army recruits. In both cases, as well as in most available studies, aggregate conditions such as infectious vs. non-infectious diseases or diseases sensitive to nutrition vs. diseases not sensitive to nutrition are considered without a detailed analysis of specific conditions. Our analysis of tuberculosis constitutes an initial attempt to isolate specific disease mortality in historical populations. ${ }^{4}$

The rest of the paper proceeds as follows: Section 2 provides some background on the epidemiology and history of tuberculosis. Section 3 describes the Union Army data and some of the variables used to test the proposed explanations. Section 4 presents the main results of the paper. We conduct the analysis in terms of the number of days free from tuberculosis through competing risk models and proportional hazards. The analysis of tuberculosis mortality is carried out in Section 5 . We compute the contribution of different factors in the mortality decline in Section 6 . Section 7 concludes the paper.

\footnotetext{
4 The paper also highlights the importance of conditions in early-life for health and mortality at later ages stressed by Barker (1994). For a summary (see Elo and Preston, 1992). In historical research, the role of early-life has been stressed by Fogel (1997), Bengtsson and Lindström (2000), among many others.
} 


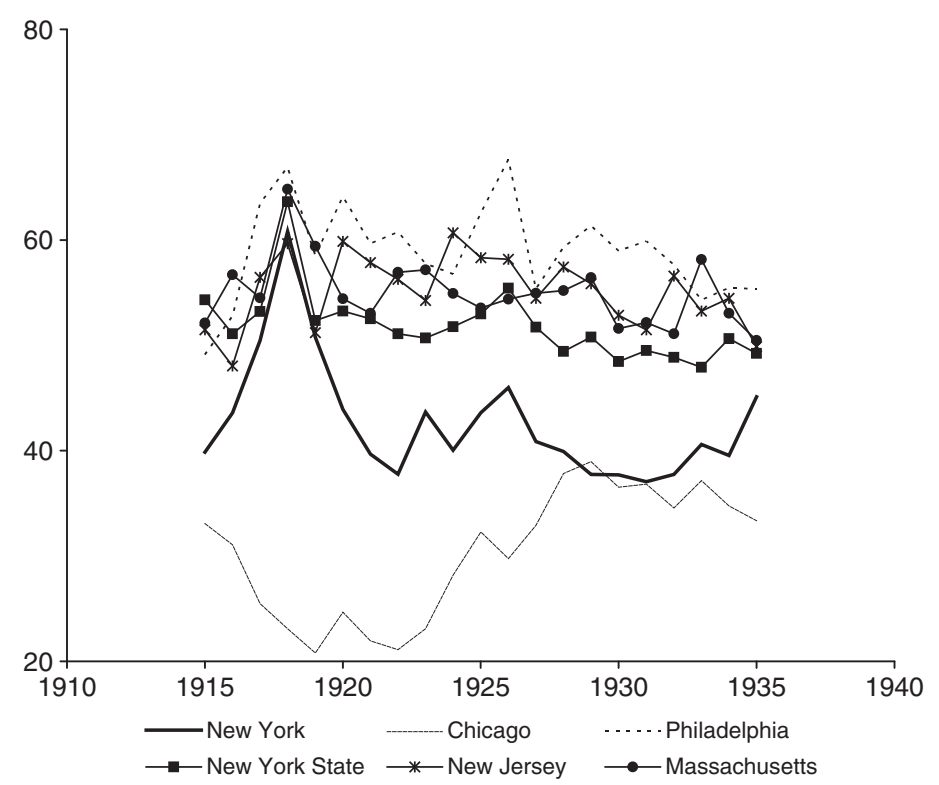

Fig. 2. Case-fatality rates (per 100 cases) from tuberculosis between 1915 and 1935. Information for New York, New York State, and Massachusetts is from pulmonary cases. Data for Chicago, Philadelphia, and New Jersey is for all forms of tuberculosis. The year 1918 represents the year of the influenza pandemic. Data based on Drolet (1938).

\section{Epidemiology, history, and some hypotheses}

Tuberculosis is a chronic infectious disease most commonly associated with the lungs. TB can affect almost any tissue or organ, but pulmonary tuberculosis represents between 80 and $90 \%$ of all known cases, a disease that is relatively easy to diagnose in its lethal stages. ${ }^{5}$ Infected individuals develop a latent or persistent infection that can remain viable throughout their host lives until resistance fails, whereupon the disease activates (see Comstock and Cauthen, 1993; Johnson, 1993 for summaries of TB's etiology and epidemiology).

Activation of the disease depends on host factors such as age and nutritional status. Infancy, puberty, and old age are periods of low resistance and high susceptibility to tuberculosis (Comstock et al., 1974; Dutt and Stead, 1999; Meyer, 1949). In addition, nutrition plays a key role in TB etiology according to epidemiological and laboratory evidence (see, for example Chandra, 1996; Raloff, 1996). People with good diets are less susceptible to the disease than individuals who suffer from malnutrition or those with a poor diet. ${ }^{6}$

As progression into active tuberculosis varies with nutritional status, disease loads have a synergistic effect on tuberculosis mortality. The presence of typhoid fever, for example, increases the risk of tuberculosis, Ferrie and Troesken (2005). ${ }^{7}$ Income and socioeconomic measures also affect progression rates to active TB (Felton and Ford, 1993; Hawker et al., 1999). ${ }^{8}$ Waaler (1984) studied the relationship between height, weight, and body mass index (BMI) and a range of different causes of death. For tuberculosis, he found that adult height was inversely related to the risk of mortality. According to Tverdal (1988), the incidence of pulmonary tuberculosis is also greater at lower BMI levels.

Environmental factors such as crowding at home and at the workplace, occupation, childhood diseases, and pathogenic loads can also trigger the acquisition and activation of tuberculosis. Occupation and working conditions also tend to affect the outcome of the disease; workers in "dusty trades" inhale particulate matter that inflames the lungs and increases their risk of developing the disease. The physical exertion and stress of exhausting activities also magnify the risk of developing tuberculosis, as does smoking. Stress factors that lead to decreased immune function also contribute to the development of tuberculosis (see Johnson, 1993).

In terms of historical trends, because of overcrowding, poor living conditions, and increased exposure, tuberculosis was more common in cities than in rural areas during the late eighteenth century. The mortality rate in cities was higher than at national

\footnotetext{
${ }^{5}$ As Olmstead and Rhode $(2004,735)$ note, there are many strains of tuberculosis, but with the exception of bovine tuberculosis, "they were of relatively minor significance to human health." Olmstead and Rhode (2004) also note that the precise fraction of bovine cases is unknown, but "it is probable that 10\% or more of these TB sufferers had contracted the bovine form of the disease." We are unable to differentiate between the many forms of the disease in our analysis.

${ }^{6}$ Protein deficiency is particularly dangerous, especially the lack of animal proteins. In fact, as Comstock and Cauthen (1993) note, a benefit of being overweight is the association with protection against tuberculosis. Puranen (1991) presents a summary of the relationship between nutrition and tuberculosis. Chandra $(1996,14304)$ discusses in detail the mechanisms responsible for the effect of protein on tuberculosis using laboratory evidence from young adult mice.

7 The complementarity effects are present for other airborne and waterborne diseases. They are perhaps better illustrated in the urban mortality transition (see Preston and Van de Walle, 1978; Ferrie and Troesken, 2005). Disease loads also have selective effects in tuberculosis mortality. Noymer and Garenne (2004) argue that the 1918 influenza pandemic generated excessively high mortality rates from tuberculosis in 1918 and hence lowered the transmission of the disease in subsequent years (as the pandemic reduced exposure to tuberculosis).

8 The resurgence of tuberculosis in Britain after 1980 also correlates with poverty rates and socioeconomic factors, (see Bhatti et al., 1995 ; Mangtani et al., 1995; Raviglione et al., 1995; Spence et al., 1993; Tocque et al., 2001). Additional studies about the effect of socioeconomic conditions on tuberculosis are listed in Lowell (1969, chap. 5).
} 
Table 1

Descriptive statistics for TB occurrence.

\begin{tabular}{lrr}
\hline & Mean & Standard deviation \\
\hline A. Rates $(\times 1000)$ & & \\
Diagnosis of TB & 20.19 & 140.56 \\
Discharge due to TB & 10.75 & 103.12 \\
Unfit due to TB & 17.13 & 129.78 \\
Death from TB (during war) & 0.87 & 295.29 \\
Death from TB (all years) & 31.77 & 175.45 \\
& & 271 \\
B. Number of days & & 332 \\
Before diagnosis of TB & 395.64 & 330.06 \\
Before discharge due to TB & 408.96 & 403.04 \\
Unfit for service & 61.62 & 25.81 \\
\hline
\end{tabular}

The number of observations is 25,208 .

levels and, on average, tended to be near 7-10 deaths per thousand. In 1850, tuberculosis mortality rates in the principal U.S. cities were above 5 deaths per thousand (see Grigg, 1958; Ferrie, 2001).

In the U.S., mortality from tuberculosis began to decline in the mid-nineteenth century, Sagan (1987, Fig. 2.1). Death rates declined mainly due to changes in the fraction of people acquiring or developing the infection and not due to changes in the case fatality of tuberculosis. ${ }^{9}$ As Drolet (1938) showed, case fatality ratios for tuberculosis, for almost all ages, varied very little over time in American cities before 1938 even though the incidence of the disease declined 50\% (Fig. 2). Sweden shared a similar decline in prevalence and a somewhat constant case fatality ratio (Puranen, 1991). Aside from the outbreaks during both world wars (see Wolff, 1940; Dubos and Dubos, 1953), mortality from TB declined gradually throughout most of the twentieth century in northwestern Europe and North America.

As we noted in the introduction, the literature has proposed many hypotheses for the decline in tuberculosis mortality. ${ }^{10}$ For convenience, in order to examine the contribution of different aspects to the mortality decline from TB, we have grouped the factors proposed to explain the decline into the following non-exclusive five categories:

A) Variables that reflect nutritional status and host susceptibility to tuberculosis such as height, weight, BMI, and age.

B) Disease experience and energy claims that decreased immune function.

C) Physical stress and energy-demanding activities.

D) Living conditions and the disease environment in early life.

E) Occupational characteristics that affect exposure to harmful dust, fumes, and other risks.

The above categories cannot be treated as independent because all five are related to the nutritional status or the health capital stock. Since health is an outcome measure, the decomposition is useful, not because it gives causal relationships between different factors, but because it suggests which inputs had a larger effect on health production. Separately, the variables listed reflect different aspects of the production of health and influences that do not necessarily overlap.

Variables in A are indicators of early life conditions (i.e., height) or contemporary nutritional status (i.e., weight and BMI) while variables in B reflect the exposure to contemporaneous diseases. Final height reflects disease experience, living conditions, and stress during the growing years (including the fetal period), so disease exposure in adulthood cannot affect final height (other indirect influences might still exist). ${ }^{11}$ Variables in $\mathrm{C}$ also represent a reduction in energy available, but the claims are taken for aspects other that disease loads. Environmental factors and living conditions, in D and E, represent influences that could in part be responsible for changes in final height but also changes in susceptibility, exposure, and predisposition to the disease. In the past, the high prevalence of tuberculosis in certain occupations has been documented for cases such as miners and textile workers, see Lowell (1969, 87-93) and Ferrie, (2001, 16-17).

\section{Union Army data}

The data employed in the paper are drawn from the Military Service Records of the Early Indicators Project described in Fogel (2000). The primary sample consists of 35,747 white males mustered into the Union Army during the Civil War. Available information on military, socioeconomic, and medical variables for these men is derived from several sources throughout their

\footnotetext{
${ }^{9}$ In Massachusetts, mortality from pulmonary tuberculosis declined from 4 deaths per thousand in 1857 to less than 1 at around 1920 , while in the U.S. tuberculosis death rates fell by $77 \%$ from 1900 to 1935 Sagan $(1987,28)$.

10 While several therapies were attempted against tuberculosis, no effective treatment was available before 1950. Bryder (1988) studied several measures against TB. As the Medical History of the Civil War (United States Army Surgeon General's Office, 1990), VI, 828) indicates, the method of treatment for tuberculosis involved the administration of cod-liver oil, tonics, and stimulants, with extra or generous diet and warm clothing. At night, doctors used opiates to relieve restlessness and coughing.

${ }^{11}$ Height, however, could still lower the exposure to airborne diseases other than TB or to waterborne diseases in general; such an effect could affect tuberculosis indirectly by lowering disease loads. In that sense, the decomposition measures the total predictive effect of height on the prevalence of tuberculosis and not its causal effect on tuberculosis.
} 
Table 2

Descriptive statistics

\begin{tabular}{|c|c|c|}
\hline & Mean & Standard deviation \\
\hline \multicolumn{3}{|l|}{ A. Nutritional status and susceptibility } \\
\hline Height (in meters) & 1.71 & 0.07 \\
\hline Weight after 1875 (in kg) (Obs. $=14,531)$ & 67.91 & 9.80 \\
\hline Age at enlistment & 25.71 & 7.81 \\
\hline Enlistment year & 1862.58 & 1.47 \\
\hline Log of property wealth in 1860 (Obs. $=4,866)$ & 6.07 & 1.14 \\
\hline \multicolumn{3}{|l|}{ B. Disease experience during war $(\times 100)$} \\
\hline Diarrhea and dysentery & 26.57 & 44.17 \\
\hline Fever & 21.06 & 40.77 \\
\hline Malaria & 2.86 & 16.67 \\
\hline Measles & 3.48 & 18.34 \\
\hline Typhoid & 4.95 & 21.69 \\
\hline Pneumonia & 3.75 & 19.05 \\
\hline Bronchitis & 4.61 & 20.98 \\
\hline Influenza & 0.52 & 7.24 \\
\hline Pleuritis & 1.01 & 10.01 \\
\hline \multicolumn{3}{|l|}{ C. War-related variables $(\times 100)$} \\
\hline Gun-shot wound (GSW) & 15.76 & 36.44 \\
\hline Number of battles & 58.68 & 129.26 \\
\hline POW & 8.34 & 27.65 \\
\hline \multicolumn{3}{|l|}{ D. Population size at enlistment $(\times 100)$} \\
\hline$<2500$ & 88.01 & 32.49 \\
\hline $2500-25,000$ & 7.41 & 26.19 \\
\hline $25,000-50,000$ & 0.78 & 8.78 \\
\hline$\geq 50,000$ & 3.80 & 19.14 \\
\hline Infectious disease mortality in $1850(\times 100)($ Obs. $=4748)$ & 37.78 & 19.78 \\
\hline \multicolumn{3}{|l|}{ E. Occupation at enlistment $(\times 100)$} \\
\hline Farmer & 51.55 & 49.97 \\
\hline Professional & 8.59 & 28.03 \\
\hline Laborer & 19.76 & 39.82 \\
\hline \multicolumn{3}{|l|}{ Artisan in } \\
\hline "Dusty" trades & 3.72 & 18.94 \\
\hline Other & 16.19 & 36.84 \\
\hline
\end{tabular}

The number of observations is 25,208 . Infectious disease mortality is the fraction of infectious diseases to overall deaths in the county of enlistment in 1850 . "Dusty" trades include painters, brickmasons, bricklayers, blacksmiths, miners, and coal workers.

lifetimes. The "Military, Pension, and Medical Records," which is the largest data set in the EI project, is derived from militaryrelated documents housed in the National Archives in Washington, D.C.

There are four main sets of variables in which we can identify whether tuberculosis was ever diagnosed and reported for any recruit from the beginning of the war onwards. They are: i) if the recruit was ever hospitalized due to tuberculosis, ii) if the recruit was ever discharged from duty due to tuberculosis, iii) if the recruit was ever considered unfit for duty due to tuberculosis, and iv) if the cause of death was associated with tuberculosis.

Table 1 describes the information available for the previous four cases. ${ }^{12}$ The total number of observations is nearly 25,000 with $2 \%$ of the recruits diagnosed with tuberculosis and $1 \%$ discharged due to the disease (similar rates were characteristic of mortality in nineteenth-century populations). The fraction of recruits unfit for service is $1.7 \%$, and deaths from $\mathrm{TB}$ occur in less than $1 \%$ of the cases. Based on estimates of case fatality rates described in Fig. 2, say 50\%, a mortality rate consistent with the discharge of tuberculosis should be around 5 per thousand (near the level of mortality during World War I in Austria in Fig. 1 and in nineteenthcentury cities). Deaths from tuberculosis were uncommon during the war because regiments were relieved of their recruits by discharge and not by death. A mortality rate of 0.8 per thousand in Table 1 is well below mortality rates from tuberculosis at the time of the Civil War so an analysis of mortality would produce unreliable estimates (to study mortality from tuberculosis, we will consider medical histories of army veterans after 1890). Mortality, however, increased substantially as the recruits aged, causing $3 \%$ of all deaths in the sample.

From Table 1 it is important to notice that, on average, discharge and diagnosis took place after a year in service and that the cases reported extend well over three years. The importance of the previous statistic relies on the fact that the length of time

\footnotetext{
12 A total of 13,499 cases of tuberculosis were reported among the white troops in the Union Army. Of all instances, 5286 cases terminated in deaths (a case fatality rate of 39\%, well in line with Fig. 2). Annual rates correspond to 6.1 and 2.2, respectively, see Medical History of the Civil War (United States Army Surgeon General's Office, 1990) (VI, pp. 818). Discharges due to tuberculosis were 12,190, so "at least 12,190 +5286=17,476 cases of consumption that may be accepted as truly resulting from the exposures, fatigues and privations of the war."
} 
Table 3

Cox proportional hazard model for diagnosis and discharge from TB.

\begin{tabular}{|c|c|c|c|c|}
\hline & \multicolumn{2}{|l|}{ Diagnosis } & \multicolumn{2}{|l|}{ Discharge } \\
\hline & Hazard ratio & S. e. & Hazard ratio & S. e. \\
\hline \multicolumn{5}{|l|}{ A. Nutritional status and susceptibility } \\
\hline Complete height (in meters) & $0.860^{* *}$ & 0.064 & $0.666^{* *}$ & 0.081 \\
\hline Age at enlistment & $1.028^{* * *}$ & 0.006 & $1.042^{* *}$ & 0.007 \\
\hline Enlistment year & $0.915^{* *}$ & 0.042 & $0.858^{* *}$ & 0.041 \\
\hline \multicolumn{5}{|l|}{ B. Infectious disease experience } \\
\hline Diarrhea and dysentery & $8.175^{* * *}$ & 0.195 & $7.286^{* * *}$ & 0.295 \\
\hline Fever & $4.450 * * *$ & 0.224 & $3.675^{* * *}$ & 0.316 \\
\hline Malaria & 0.843 & 0.410 & 0.794 & 0.601 \\
\hline Measles & $7.536^{* * *}$ & 0.330 & $5.373^{* * *}$ & 0.474 \\
\hline Typhoid & $9.938^{* * *}$ & 0.235 & $7.680^{* * *}$ & 0.304 \\
\hline Pneumonia & $11.684^{* * *}$ & 0.225 & $8.374^{* * *}$ & 0.314 \\
\hline Bronchitis & $1.645^{* *}$ & 0.246 & 1.485 & 0.383 \\
\hline Influenza & 4.308 & 1.064 & $10.909^{* *}$ & 1.137 \\
\hline \multicolumn{5}{|l|}{ C. Stress and war-related variables } \\
\hline Gun-shot wound (GSW) & $6.804^{* * *}$ & 0.299 & 1.687 & 0.511 \\
\hline Number of battles & $0.738^{* * *}$ & 0.054 & $0.576^{* * *}$ & 0.098 \\
\hline POW & 0.768 & 0.194 & 0.664 & 0.275 \\
\hline \multicolumn{5}{|c|}{ D. Population at enlistment ( $\geq 50,000$ omitted) } \\
\hline$<2500$ & 1.263 & 0.282 & 1.190 & 0.391 \\
\hline $2500-25,000$ & 1.082 & 0.322 & 1.725 & 0.425 \\
\hline $25,000-50,000$ & $2.868^{* *}$ & 0.468 & 0.609 & 1.072 \\
\hline \multicolumn{5}{|c|}{ E. Occupation at enlistment (laborer omitted) } \\
\hline Farmer & 1.038 & 0.140 & 1.296 & 0.194 \\
\hline Professional & 1.288 & 0.203 & 1.131 & 0.293 \\
\hline Artisan & 0.957 & 0.168 & 1.005 & 0.233 \\
\hline$\chi^{2}$ for likelihood ratio & 846.91 & & 426.65 & \\
\hline Observations (events) & $18,504(456)$ & & $18,504(269)$ & \\
\hline
\end{tabular}

Days free from diagnosis and discharge due to TB are measured from enlistment. S. e. represents standard errors. Individuals who died of or were discharged due to a cause of death other than TB are treated as censored. The first instance of tuberculosis diagnosis and discharge is an event. Completed height controls for individuals aged below 25 and above 45 . Disease experience, battles, and gun-shot wounds are time-varying. The proportional hazards assumption is tested by testing the slope on the generalized Schoenfeld residuals as a function of time.

** The coefficient is significantly different from 1 at the $5 \%$ level.

*** The coefficient is significantly different from 1 at the $1 \%$ level.

before diagnosis is sufficient for the presence of severe cases of the disease. In contrast to the analysis of soldiers unfit for service, which took place nearly two months after enlistment, diagnosis and discharge provide enough time for tuberculosis to develop while in the army. ${ }^{13}$ To minimize the risk of considering cases of tuberculosis not related to the war experience, we will study only diagnosis and discharge.

Table 2 includes descriptive statistics for the variables used in the regressions divided into the five categories listed above. In the sample, height was on average of $1.71 \mathrm{~m}$, and age at enlistment was 25 years. Weight, and hence BMI, are available only after 1875 so we will use it to study the mortality of veterans. Personal property wealth was obtained from linkages to the 1860 Federal Census for a smaller sample. The main occupation was farming, and more than $85 \%$ of the population enlisted from towns with populations of less than 2500 inhabitants. Recruits fought on average 0.6 battles, and $8 \%$ were POWs. Infectious diseases during the war were highly prevalent. More than $25 \%$ of the soldiers experienced at least one episode of diarrhea, more than $20 \%$ experienced fevers, and nearly $10 \%$ experienced a respiratory infection.

\section{Empirical framework and results}

Our empirical framework uses a competing risk hazard model for the number of days free from tuberculosis treating individuals who died or were discharged due to a cause other than TB as censored. Tuberculosis can remain inactive in an asymptomatic patient so we assume that cases of tuberculosis in our sample correspond to activation of the disease. Recruits may

\footnotetext{
13 As the Medical History of the Civil War United States Army Surgeon General's Office (1990, VI, pp. 818) notes: “[The] number of cases includes an unknown but certainly large percentage of individuals whose consumptive tendencies were so marked at the period of enlistment that they should not have been received into the service. On reaching their regiments from the recruiting depots [,] their names were placed on the sick report by the regimental medical officers, and proceedings were instituted to effect their discharge."
} 
Table 4

Cox proportional hazard model for the diagnosis of tuberculosis.

\begin{tabular}{|c|c|c|c|c|c|c|c|c|}
\hline & Hazard ratio & S. e. & Hazard ratio & S. e. & Hazard ratio & S. e. & Hazard ratio & S. e. \\
\hline \multicolumn{9}{|l|}{ A. Nutritional status } \\
\hline Log (property wealth, 1860) & 1.014 & 0.098 & - & - & - & - & - & - \\
\hline Share of inf. disease mortality, 1850 & - & - & 1.328 & 0.58 & - & - & - & - \\
\hline Log of total inf. deaths, 1850 & - & - & - & - & 1.055 & 0.070 & - & - \\
\hline Complete height & 0.611 & 0.197 & 0.860 & 0.132 & 0.859 & 0.136 & $0.826^{* *}$ & 0.077 \\
\hline Age at enlistment & $1.073^{* *}$ & 0.028 & $1.030^{* *}$ & 0.013 & $1.031^{* *}$ & 0.013 & $1.025^{* *}$ & 0.007 \\
\hline Enlistment year & $0.766^{* *}$ & 0.109 & $0.844^{* *}$ & 0.053 & $0.840^{* *}$ & 0.052 & $0.867^{* *}$ & 0.042 \\
\hline \multicolumn{9}{|l|}{ B. Infectious disease experience } \\
\hline Diarrhea and dysentery & $18.965^{* * *}$ & 0.577 & $4.245^{* *}$ & 0.736 & $4.393^{* *}$ & 0.737 & $9.917^{* * *}$ & 0.262 \\
\hline Fever & $19.194^{* * *}$ & 0.848 & $10.461^{* * *}$ & 0.741 & $10.332^{* * *}$ & 0.740 & $3.426^{* * *}$ & 0.291 \\
\hline Malaria & $0.033^{* * *}$ & 1.265 & 2.940 & 0.809 & 2.878 & 0.811 & 0.713 & 0.499 \\
\hline Measles & 2.572 & 0.834 & $20.769^{* * *}$ & 0.738 & $20.875^{* * *}$ & 0.735 & $3.365^{* * *}$ & 0.444 \\
\hline Typhoid & $18.387^{* * *}$ & 0.522 & $21.844^{* * *}$ & 0.663 & $21.701^{* * *}$ & 0.599 & $13.105^{* * *}$ & 0.241 \\
\hline Pneumonia & $74.350^{* * *}$ & 0.446 & $8.478^{* * *}$ & 0.686 & $8.424^{\text {*** }}$ & 0.683 & $11.625^{\text {*** }}$ & 0.264 \\
\hline Bronchitis & 0.384 & 1.269 & 0.853 & 0.822 & 0.836 & 0.816 & $3.295^{* * *}$ & 0.319 \\
\hline Influenza & 4.244 & 1.718 & - & - & - & - & - & - \\
\hline Pleuritis & $16.154^{* * *}$ & 1.053 & $76.353^{* * *}$ & 1.028 & $80.289^{* * *}$ & 1.027 & $7.934^{\text {*** }}$ & 0.563 \\
\hline \multicolumn{9}{|l|}{ C. War-related variables } \\
\hline Gun-shot wound & 1.190 & 1.250 & $141.779^{* * *}$ & 0.677 & $143.873^{\text {*** }}$ & 0.673 & - & - \\
\hline Number of battles & $0.735^{* * *}$ & 0.132 & $0.541^{\text {*** }}$ & 0.157 & $0.544^{* * *}$ & 0.158 & - & - \\
\hline POW & 0.434 & 0.520 & 0.592 & 0.519 & 0.575 & 0.521 & - & - \\
\hline \multicolumn{9}{|c|}{ D. Population at enlistment ( $\geq 50,000$ omitted) } \\
\hline$<2500$ & 3.291 & 1.029 & - & - & - & - & 1.145 & 0.365 \\
\hline $2500-25,000$ & 3.092 & 1.099 & 0.818 & 0.56 & 0.825 & 0.560 & 1.259 & 0.411 \\
\hline $25,000-50,000$ & - & - & - & - & - & - & 2.330 & 0.615 \\
\hline \multicolumn{9}{|c|}{ E. Occupation at enlistment (laborer omitted) } \\
\hline Farmer & 0.828 & 0.328 & 1.047 & 0.339 & 1.089 & 0.344 & 1.284 & 0.182 \\
\hline Professional & 0.683 & 0.549 & 1.387 & 0.516 & 1.400 & 0.515 & $1.614^{* * *}$ & 0.254 \\
\hline Artisan & 0.893 & 0.422 & 1.506 & 0.390 & 1.498 & 0.390 & 1.132 & 0.214 \\
\hline$\chi^{2}$ for likelihood ratio & 202.72 & & 204.73 & & 205.07 & & 522.69 & \\
\hline Observations (events) & $4098(100)$ & & 3801 (97) & & $3801(97)$ & & $11,685(313)$ & \\
\hline Proportional hazards & $6.49^{* *}$ & & 0.84 & & 0.84 & & 1.02 & \\
\hline
\end{tabular}

Property wealth from the 1860 Federal Census. Share of inf. disease mortality is the fraction of infectious diseases to overall deaths in the county of enlistment in 1850. Log of total inf. deaths is the log of the total number of deaths from infectious diseases in the county of enlistment in 1850 . Additional definitions as in Table 3.

** The coefficient is significantly different from 1 at the $5 \%$ level.

*** The coefficient is significantly different from 1 at the $1 \%$ level.

have been observationally at risk prior to enlistment but the information for the Union Army does not allow one to consider a more precise measure of days free from tuberculosis. We will consider explicit controls for the acquisition of tuberculosis in our analysis of mortality in Section 5. The empirical results are based on a Cox proportional hazard model:

$$
h(t \mid \mathbf{x} \beta)=h_{0}(t) \exp \left\{x_{A} \beta_{A}+x_{B} \beta_{B}+x_{C} \beta_{C}+x_{D} \beta_{D}+x_{E} \beta_{E}\right\}
$$

where $h_{0}(t)$ is the baseline hazard, $\mathbf{x}$ is a vector of observed variables from the five categories mentioned above, and $\beta$ is a vector of associated coefficients (or risk scores). The hazard rate $h(t \mid \mathbf{x} \beta)$ is an exponential function of the covariate vector $\mathbf{x}$ so the logarithm of the baseline hazard $h_{0}(t)$ can be considered as a constant (not explicitly described). The effect of a one-unit change in a covariate, say $x_{A}$, affects the logarithm of the hazard by $\beta_{A}$, so the estimated effect on the hazard itself is exp $\left\{\beta_{A}\right\}$, which corresponds to the reported hazard rate. If the reported hazard rates equal to 1 , that implies a coefficient of zero (as $\ln \{1\}=0$ ) while a hazard below 1 represents a negative coefficient or a reduced risk. Covariates with hazard rates above 1 indicate an increased risk.

We study the length of time between enlistment and the diagnosis and discharge date. It is very likely that the presence of tuberculosis was associated with higher risks of developing additional conditions so controls must take into account the timing of the disease in order to make the claims precise. To resolve causal ordering, we consider the prevalence of the different diseases in category B, the number of battles, and gun-shot wounds (GSW) while in the army as time-varying covariates. That is, we consider the presence of the condition before tuberculosis diagnosis or discharge. Obviously, the fact that we consider conditions before the presence of tuberculosis does not eliminate a "third factor" that may influence tuberculosis and other diseases. We present some remarks on this concern later on in this section.

Table 3 presents the results for TB diagnosis and discharge. In both cases, we cannot reject the hypothesis that all coefficients are jointly statistically different from 1 . This suggests that the factors that are proposed help explain the prevalence of tuberculosis. 
Table 5

Cox proportional hazard model for discharge of tuberculosis.

\begin{tabular}{|c|c|c|c|c|c|c|c|c|}
\hline & Hazard ratio & S. e. & Hazard ratio & S. e. & Hazard ratio & S. e. & Hazard ratio & S. e. \\
\hline \multicolumn{9}{|l|}{ A. Nutritional status } \\
\hline Log (property wealth, 1860) & 0.946 & 0.126 & - & - & - & - & - & - \\
\hline Share of inf. disease mortality, 1850 & - & - & 2.175 & 0.893 & - & - & - & - \\
\hline Log of total inf. deaths, 1850 & - & - & - & - & 0.835 & 0.106 & - & - \\
\hline Complete height & $0.428^{* *}$ & 0.228 & $0.395^{* *}$ & 0.234 & $0.410^{* *}$ & 0.231 & $0.613^{* * *}$ & 0.094 \\
\hline Age at enlistment & $1.21^{* * *}$ & 0.024 & 1.027 & 0.018 & 1.023 & 0.018 & $1.043^{* * *}$ & 0.007 \\
\hline Enlistment year & $0.650^{* * *}$ & 0.149 & $0.791^{* * *}$ & 0.069 & $0.779^{* * *}$ & 0.073 & $0.850^{* * *}$ & 0.041 \\
\hline \multicolumn{9}{|l|}{ B. Infectious disease experience } \\
\hline Diarrhea and dysentery & $5.856^{* *}$ & 1.102 & 0.267 & 1.333 & 0.3205 & 1.352 & $6.439^{* * *}$ & 0.359 \\
\hline Fever & $144.370^{* * *}$ & 0.576 & $24.964^{* * *}$ & 1.147 & $31.411^{* * *}$ & 1.153 & $3.911^{* * *}$ & 0.382 \\
\hline Malaria & $164.512^{* * *}$ & 1.741 & $26.736^{* *}$ & 1.461 & $28.265^{* *}$ & 1.454 & 0.612 & 0.795 \\
\hline Measles & $6.036^{* *}$ & 0.905 & $54.481^{* * *}$ & 0.848 & $67.564^{* * *}$ & 0.850 & $4.528^{* * *}$ & 0.555 \\
\hline Typhoid & 0.285 & 1.335 & $32.901^{* * *}$ & 0.665 & $42.281^{* * *}$ & 0.674 & $6.941^{* * *}$ & 0.348 \\
\hline Pneumonia & $30.226^{* * *}$ & 0.626 & 1.361 & 1.682 & 1.464 & 1.648 & $9.458^{* * *}$ & 0.350 \\
\hline Bronchitis & 5.920 & 0.919 & 1.164 & 0.982 & 1.036 & 0.976 & 1.686 & 0.494 \\
\hline Pleuritis & 5.846 & 1.295 & $94.927^{* *}$ & 1.047 & $99.972^{* * *}$ & 1.045 & $9.230^{* *}$ & 0.683 \\
\hline \multicolumn{9}{|l|}{ C. War-related variables } \\
\hline Gun-shot wound & $0.004^{* * *}$ & 1.783 & - & - & - & - & - & - \\
\hline Number of battles & $0.418^{* * *}$ & 0.271 & $0.392^{* * *}$ & 0.294 & 0.374 & 0.293 & - & - \\
\hline POW & 0.370 & 0.736 & 0.649 & 0.740 & 0.685 & 0.743 & - & - \\
\hline \multicolumn{9}{|c|}{ D. Population at enlistment ( $\geq 50,000$ omitted) } \\
\hline$<2500$ & 1.713 & 1.052 & 1.764 & 1.040 & 1.047 & 1.045 & 1.186 & 0.458 \\
\hline $2500-25,000$ & 3.973 & 1.097 & 3.251 & 1.182 & 2.130 & 1.185 & 1.678 & 0.501 \\
\hline $25,000-50,000$ & - & - & 5.654 & 1.439 & 3.909 & 1.437 & 0.794 & 1.099 \\
\hline \multicolumn{9}{|c|}{ E. Occupation at enlistment (laborer omitted) } \\
\hline Farmer & 1.962 & 0.533 & 0.958 & 0.505 & 0.843 & 0.509 & 1.173 & 0.222 \\
\hline Professional & 0.973 & 0.743 & 0.419 & 1.102 & 0.424 & 1.102 & 1.353 & 0.315 \\
\hline Artisan & 1.341 & 0.633 & 1.665 & 0.564 & 1.739 & 0.565 & 0.985 & 0.265 \\
\hline
\end{tabular}

Property wealth from the 1860 Federal Census. Share of inf. disease mortality is the fraction of infectious diseases to overall deaths in the county of enlistment in 1850. Log of total inf. deaths is the log of the total number of deaths from infectious diseases in the county of enlistment in 1850 . Additional definitions as in Table 3 .

$* *$ The coefficient is significantly different from 1 at the $5 \%$ level.

*** The coefficient is significantly different from 1 at the $1 \%$ level.

We test the proportionality assumption using a generalized test on the slope of the Schoenfeld residuals, see Lawless (2003, 363). In Table 3, the hypothesis of proportional hazards cannot be rejected.

With the exception of occupational measures, variables in all categories have a predictive power for the diagnosis of and discharge due to tuberculosis while in the army. Our findings for height indicate that taller recruits were less likely to develop tuberculosis during the war and to be discharged for that condition. Height is statistically significant for diagnosis and discharge even after controlling for initial exposure to diseases through population size at enlistment. We will provide additional remarks about the role of early life conditions later on. An increase in $1 \mathrm{~cm}$ in height reduced the hazard of diagnosis by about $0.15 \%$ and the hazard of discharge by about $0.35 \%$. That is, since the hazard for height in Table 3 is 0.86 , its coefficient is $\ln \{0.86\}=-0.15$, so an increase in $1 \mathrm{~cm}$ in height reduces the exponential of hazard by $-0.15 \times 0.01$; a $0.15 \%$ reduction.

Older recruits were more likely to develop TB as well as recruits who enlisted later in the war. ${ }^{14}$ Physical symptoms of tuberculosis include fever, sweating at night, coughing and difficult breathing, spitting up blood, and loss of weight. However, none of these symptoms is peculiar to TB; continued ill-health was probably the most constant symptom. Due to the symptoms, it is not surprising to find fever as a significant predictor of diagnosis and discharge. Respiratory diseases also increase susceptibility to the infection. Pneumonia, measles, and pleuritis were significant predictors of TB diagnosis and discharge and were associated with higher risks of tuberculosis. Influenza was a predictor of TB discharge but had no important effect on diagnosis, and bronchitis was a predictor of diagnosis but had no effect on discharge. Recruits suffering from pleuritis and pneumonia were several times more likely to later be diagnosed and discharged due to tuberculosis.

\footnotetext{
${ }^{14}$ It is possible that a less strict rejection policy was implemented later in the war. The fact that in 1863 recruitment had to rely on a draft seems to suggest this as a possibility. The Provost Marshall General (United States Provost Marshall General (1875, Vol. 2, 638-767)) includes reports on rejection rates by states on the grounds of tuberculosis. Of 305,608 people examined and rejected, $3.272 \%$ were rejected due to tuberculosis. The highest fraction of rejections was observed in Maryland (nearly 15\%), and California had the lowest rejection rate due to TB (0.4\%). The results obtained in Table 3 remain unaffected once state rejection rates due to tuberculosis are included, but unfortunately, as we mentioned above, rejection rates vary only between states and not over time.
} 
Table 6

Cox proportional hazard model for discharge of tuberculosis.

\begin{tabular}{|c|c|c|c|c|c|c|c|c|}
\hline & Hazard ratio & S. e. & Hazard ratio & S. e. & Hazard ratio & S. e. & Hazard ratio & S. e. \\
\hline \multicolumn{9}{|l|}{ A. Nutritional status } \\
\hline Height $^{2}$ & $3.021^{* *}$ & 0.289 & - & - & - & - & - & - \\
\hline Age $\times$ height & - & - & $1.109^{* *}$ & 0.033 & - & - & - & - \\
\hline Rejection rates due to $\mathrm{TB}$ & - & - & - & - & 1.030 & 0.857 & - & - \\
\hline Complete height & $0.649^{* *}$ & 0.080 & $0.658^{* *}$ & 0.080 & $0.669^{* *}$ & 0.081 & $0.665^{* *}$ & 0.081 \\
\hline Age at enlistment & $1.039^{* *}$ & 0.007 & $0.869^{* * *}$ & 0.059 & $1.042^{* * *}$ & 0.007 & $1.042^{* *}$ & 0.007 \\
\hline Enlistment year & $0.868^{* *}$ & 0.042 & $0.864^{* *}$ & 0.042 & $0.858^{* *}$ & 0.041 & $0.858^{* * *}$ & 0.041 \\
\hline \multicolumn{9}{|l|}{ B. Disease experience } \\
\hline Diarrhea and dysentery & $7.890^{* *}$ & 0.292 & $7.626^{* *}$ & 0.294 & $7.268^{* * *}$ & 0.304 & $7.246^{* *}$ & 0.295 \\
\hline Fever & $3.723^{* *}$ & 0.313 & $3.671^{* *}$ & 0.315 & $3.685^{* * *}$ & 0.324 & $3.689^{* *}$ & 0.315 \\
\hline Malaria & 0.432 & 0.665 & 0.607 & 0.628 & 0.793 & 0.601 & 0.791 & 0.600 \\
\hline Measles & $6.523^{* *}$ & 0.464 & $5.960^{* *}$ & 0.469 & $5.377^{* *}$ & 0.474 & $5.306^{* *}$ & 0.474 \\
\hline Typhoid & $7.733^{* *}$ & 0.306 & $7.756^{* *}$ & 0.304 & $7.662^{* * *}$ & 0.310 & $7.860^{* *}$ & 0.303 \\
\hline Pneumonia & $8.824^{* *}$ & 0.321 & $8.531^{* *}$ & 0.317 & $8.343^{* * *}$ & 0.332 & $8.320^{* *}$ & 0.314 \\
\hline Bronchitis & 1.335 & 0.398 & 1.397 & 0.392 & 1.485 & 0.383 & 1.502 & 0.383 \\
\hline Influenza & 7.122 & 1.144 & $8.914^{\text {*** }}$ & 1.140 & $10.956^{* *}$ & 1.143 & $10.808^{* * *}$ & 1.136 \\
\hline Pleuritis & $8.202^{*}$ & 0.628 & $8.739^{* *}$ & 0.619 & 9.426 & 0.611 & $9.379^{* * *}$ & 0.610 \\
\hline \multicolumn{9}{|l|}{ C. War-related variables } \\
\hline Gun-shot wound & 1.820 & 0.515 & 1.810 & 0.515 & 1.688 & 0.512 & 1.660 & 0.511 \\
\hline Number of battles & $0.564^{* *}$ & 0.097 & $0.570^{* *}$ & 0.0097 & $0.575^{* * *}$ & 0.100 & $0.575^{* *}$ & 0.098 \\
\hline POW & 0.666 & 0.277 & 0.666 & 0.276 & 0.665 & 0.275 & 0.666 & 0.275 \\
\hline \multicolumn{9}{|c|}{ D. Population at enlistment ( $\geq 50,000$ omitted) } \\
\hline$<2500$ & 1.127 & 0.391 & 1.165 & 0.391 & 1.190 & 0.391 & 1.200 & 0.391 \\
\hline $2500-25,000$ & 1.658 & 0.425 & 1.713 & 0.425 & 1.725 & 0.425 & 1.738 & 0.425 \\
\hline $25,000-50,000$ & 0.578 & 1.072 & 0.588 & 1.072 & 0.609 & 1.072 & 0.615 & 1.072 \\
\hline \multicolumn{9}{|c|}{ E. Occupation at enlistment (laborer omitted) } \\
\hline Farmer & 1.186 & 0.195 & 1.220 & 0.195 & 1.296 & 0.194 & 1.296 & 0.194 \\
\hline Professional & 1.104 & 0.293 & 1.107 & 0.293 & 1.132 & 0.2983 & 1.132 & 0.293 \\
\hline Artisan & 0.974 & 0.233 & 0.986 & 0.233 & 1.005 & 0.233 & - & - \\
\hline Dusty trade & - & - & - & - & - & - & 0.664 & 0.481 \\
\hline Non-dusty trade & - & - & - & - & - & - & 1.076 & 0.239 \\
\hline$\chi^{2}$ for likelihood ratio & 444.44 & & 436.32 & & 426.61 & & 427.78 & \\
\hline Observations (events) & $18,504(269)$ & & $18,504(269)$ & & $18,504(269)$ & & $18,504(269)$ & \\
\hline Proportional hazards & 0.48 & & 0.47 & & 0.50 & & 0.49 & \\
\hline
\end{tabular}

Rejection rates due to TB is the fraction of soldiers unfit for service in the county of enlistment. "Dusty" trades include painters, brickmasons, bricklayers, blacksmiths, miners, and coal workers. Additional definitions as in Table 3.

** The coefficient is significantly different from 1 at the $5 \%$ level.

*** The coefficient is significantly different from 1 at the $1 \%$ level.

There was no additional risk associated with being a POW, and soldiers suffering from gun-shot wounds were more likely to be diagnosed with tuberculosis. Instead of additional risks, participation in battles represented a reduction in the risks for diagnosis and discharge. The number of battles depended in general upon the year and place of enlistment, which have already been entered as controls in the estimation, so other mechanisms must account for the "protective" effect of war battles. We discuss this effect later on separately. Finally, dummy variables for the size of the city at enlistment in 1860 are only statistically larger than one for TB diagnosis for recruits who enlisted in cities with populations between 25,000 and 50,000.

In Tables 4 and 5 we consider alternative specifications that examine the robustness of the results. Later on, we will provide some remarks about sample selection, measurement issues, and the influence of early-life conditions. Tables 4 and 5 include property wealth for soldiers with linkages to the 1860 Federal Census. These tables also report estimates that control for the share of infectious disease mortality on overall deaths per county of enlistment and for the (logarithm of) total number of deaths from infections (and not its share) for soldiers linked to the 1850 Federal Census. The previous variables examine the relative and absolute importance of disease environments early on. That is, since the average age at enlistment was 25, infectious disease mortality in 1850 affected most soldiers at age 15.

Including wealth and infectious disease mortality drastically reduce the sample size and the number of events since there are only limited linkages to the censuses. Overall, some of the previous results are maintained, although statistical significance is often lost due to the reduced sample size. In the case of diagnosis, wealth has no influence on the disease outcomes whereas the share and log of disease mortality have a positive but insignificant effect. The estimated hazard coefficient for height is lower than in the previous tables but it is more imprecisely estimated. The influence of age at enlistment and enlistment year is maintained. In the analysis of discharge, wealth has a protective effect and the share of infectious diseases has a negative effect. In both cases, however, the results lack statistical significance. The estimated hazard for height in discharge is maintained. As before, recruits who enlisted later in the war were also more likely to suffer from tuberculosis and occupation and place of enlistment had little 
predictive power for tuberculosis. The main result from Tables 4 and 5 is that in both tables, the influence of water and airborne diseases is robust. These additional regressions also suggest limited effects of height and socioeconomic variables prior to enlistment but these effects may be due to smaller sample sizes.

Table 6 presents yet another attempt to examine the influence of early-life conditions. In this table, we include as a control the fraction of recruits unfit for service due to tuberculosis in the county of enlistment. As we noted before, about 300 recruits were found unfit for service due to tuberculosis nearly two months after enlistment, Table 1. This measure serves to complement previous analyses of disease exposure since it offers a proxy for the prevalence of tuberculosis in the county of enlistment. The hazard for this variable is larger than one indicating that soldiers who enlisted in counties with higher prevalence of TB had higher risks of being discharged from the army. The estimate, however, is not statistically different from one. Separately, since the acquisition of tuberculosis could simply be due to a disproportionate presence of the disease in a given company, we have computed company prevalence rates for tuberculosis and estimated their effect on diagnosis and discharge. It turns out that the prevalence of tuberculosis in different companies did not differ drastically so a company effect is not statistically different from $1 .^{15}$

Alternative estimates using occupations characterized as "dusty trades" could be employed to evaluate the effect of exposure to fumes or other particulate matter that inflames the lungs. Our classification is based on the occupations provided at enlistment. The results are available in Table 6, but they fail to find significant effects of occupation on tuberculosis (the analysis of diagnosis is similar to previous findings so we do not report it). The lack of significance could be due to the widespread effects of tuberculosis in the army. For instance, different occupations may induce important differences in the acquisition of the disease prior to the war but not in the activation of TB given the nature of repeated contact while in the army.

Interaction terms and non-linear effects included in a final test are also available in Table 6 . They tend to reinforce the results in Tables 3-5 for all disease loads, but the square of height has a positive and a significant effect on diagnosis and discharge. Since the square effect is large, this would suggest that taller recruits have higher risks for tuberculosis. However, there is no measure of weight in the data so it is difficult to evaluate the role of non-linear effects in height (as height often varies with weight as we will show later on). For example, if weight is held constant, BMI decreases with the square of height, i.e., BMI $=$ weight $/(\text { height })^{2}$. Thus, the negative effects of the square of height are fully consistent with soldiers having low measures of BMI and hence the interpretation of the coefficient on the square of height cannot be made independently of an assessment of the role of BMI. Once we extend the analysis to tuberculosis mortality risk, we will be able to provide a proper account of non-linearities. In fact, as we show later on, the influence of BMI is far stronger and more robust than the effects of height. In this sense, a positive non-linear effect of height is not inconsistent with the importance of nutritional status. Finally, interactions of height with age give a positive coefficient (a hazard rate of 1.08), suggesting that the benefits of height decline somewhat with age. ${ }^{16}$

In the rest of this section we examine in some more detail additional concerns associated with the diagnosis of tuberculosis, sample selection, and early-life influences. In the next section we present a complementary analysis of tuberculosis mortality that enriches the current discussion.

\subsection{Diagnosis}

Diagnosis of tuberculosis, as it is an asymptomatic disease in early stages, could be biased by unobserved factors early in life that lead to acquisition of the disease but not activation. It is not possible to determine the exact date of acquisition of the disease so our treatment of a latent case acquired in infancy or a case acquired while in service is identical as long as the conditions of war triggered activation of the disease. (In our analysis of mortality, we will use wartime disease experiences and exact measures of TB diagnosis as controls for previous acquisition of TB.) In healthy populations, activation of the disease is not very common. ${ }^{17}$

In addition to the absence of exact measures of disease acquisition, there are some concerns with the diagnosis of tuberculosis itself as no microbiological testing was available. Tuberculosis in its latest stages poses no difficulties for diagnosis because the clinical features are very distinctive. In the clinical records, there is no shortage of descriptions of the exclusive symptoms of the disease (such as expectorated and tubercular matters) and of physical signs, see Medical History of the Civil War (United States Army Surgeon General's Office, 1990, VI, pp. 818-820). Although the accuracy of diagnosis based on clinical features is not known, modern studies suggest that in areas of high prevalence, the majority of patients with clinical features of the disease will have a diagnosis of tuberculosis (see Puffer and Griffith (1967) for a study in cities in less developed countries). ${ }^{18}$

\footnotetext{
15 Companies with fewer than 50 recruits had a prevalence rate of 17.32 per 1000 while companies with more than 400 soldiers a prevalence rate of 16.34 . The highest prevalence rate, 30.22, was observed in companies with 350-399 recruits. Recall from Table 1 that the average prevalence rate was 20 per thousand.

${ }^{16}$ As an additional unreported test, we considered seasonal effects on tuberculosis. Since seasonal changes also affect metabolic rates and possibly nutritional status (through food availability and energy claims), instead of considering seasonal dummies as covariates we stratify the estimated effects of winter diagnosis and discharge defined as diagnosis or discharge during December, January, and February. (The results are not sensitive to changes in the definition of winter.) The main difference from Table 3 is a reduction in the effect of additional conditions on the risk of tuberculosis. This suggests that winter conditions were likely to increase the risk of other respiratory conditions as well but that previous predictors of tuberculosis still remain significant.

17 Among people with latent tuberculosis but no other risks, the estimated annual probability of developing symptomatic tuberculosis is only $0.1 \%$, see Ferebee et al. (1963). Immunocompromised patients, by HIV co-infection, have a risk of 5 to $10 \%$ per year of developing symptomatic tuberculosis.

18 Autopsies in multiple cases discussed in the Medical History of the Civil War United States Army Surgeon General's Office (1990) confirm the diagnosis of tuberculosis. See, Case 98 (III, pp. 103), Case 413 (III, pp. 181), Case 865 (III, pp. 259), Case 876 (III, pp 263), and Case 971 (XI, pp 651 ). A case of a GSW to the chest that served to diagnose tuberculosis is discussed in VIII, 528. Case 731 (III, pp. 231) showed signs of tuberculosis, but the cause of death was coded as anemia. Cases of tuberculosis in "young and undeveloped physically" men were discussed in (VI, pp. 757). Their diagnosis was based on "lung trouble, cough, purulent sputa or muco-purulent sputa sometimes mixed with blood and debility." The soldiers were discharged.
} 
Table 7

Cox proportional hazard model for TB diagnosis for different sub-populations.

\begin{tabular}{|c|c|c|c|c|c|c|c|c|}
\hline & \multicolumn{2}{|l|}{ Farmers } & \multicolumn{2}{|l|}{ Non-farmers } & \multicolumn{2}{|l|}{ Rural } & \multicolumn{2}{|l|}{ Non-rural } \\
\hline & Hazard ratio & S. e. & Hazard ratio & S. e. & Hazard ratio & S. e. & Hazard ratio & S. e. \\
\hline \multicolumn{9}{|c|}{ A. Nutritional status and susceptibility } \\
\hline Complete height (in meters) & $0.858^{*}$ & 0.086 & $0.853^{*}$ & 0.101 & $0.876^{*}$ & 0.068 & 0.709 & 0.204 \\
\hline Age at enlistment & $1.034^{* * *}$ & 0.008 & 1.018 & 0.011 & $1.026^{* * *}$ & 0.007 & $1.050^{* *}$ & 0.019 \\
\hline Enlistment year & $0.877^{* *}$ & 0.057 & 0.985 & 0.067 & $0.888^{* * *}$ & 0.043 & 1.216 & 0.148 \\
\hline \multicolumn{9}{|l|}{ B. Infectious disease experience } \\
\hline Diarrhea and dysentery & $9.063^{* * *}$ & 0.257 & $9.908^{* * *}$ & 0.366 & $9.623^{* * *}$ & 0.207 & 3.308 & 0.707 \\
\hline Fever & $4.084^{* * *}$ & 0.282 & 3.790 *** & 0.434 & $4.591 * * *$ & 0.249 & $5.825^{* *}$ & 0.713 \\
\hline Malaria & 2.553 & 0.592 & 0.750 & 0.682 & 0.678 & 0.442 & - & - \\
\hline Measles & $10.267^{* * *}$ & 0.401 & $3.973^{* *}$ & 0.708 & $5.038^{* * *}$ & 0.378 & $42.485^{* * *}$ & 0.744 \\
\hline Typhoid & $8.744^{* * *}$ & 0.291 & $9.931^{* * *}$ & 0.443 & $10.245^{* * *}$ & 0.263 & $12.413^{* * *}$ & 0.673 \\
\hline Pneumonia & $11.090^{* * *}$ & 0.268 & $18.294^{* * *}$ & 0.374 & $9.772^{* * *}$ & 0.238 & $291.804^{* * *}$ & 0.661 \\
\hline Bronchitis & 1.153 & 0.350 & 7.785 & 0.466 & $1.852^{* *}$ & 0.275 & $24.983^{* * *}$ & 1.148 \\
\hline Pleuritis & $36.112^{* * *}$ & 0.603 & 2.502 & 0.754 & $9.633^{* * *}$ & 0.525 & $82.371^{* * *}$ & 0.783 \\
\hline \multicolumn{9}{|l|}{ C. Stress and war-related variables } \\
\hline Gun-shot wound (GSW) & $5.580^{* * *}$ & 0.445 & $7.886^{* * *}$ & 0.457 & $6.444^{* * *}$ & 0.396 & $10.608^{* * *}$ & 0.593 \\
\hline Number of battles & $0.694^{* * *}$ & 0.082 & $0.813^{* *}$ & 0.080 & $0.757^{* * *}$ & 0.0578 & $0.591^{* *}$ & 0.235 \\
\hline POW & 1.082 & 0.242 & $0.556^{* *}$ & 0.321 & 0.934 & 0.193 & $0.026^{* *}$ & 1.678 \\
\hline$\chi^{2}$ for likelihood ratio & 543.91 & & 317.85 & & 720.27 & & 163.85 & \\
\hline Observations (events) & $10,381(263)$ & & $8,125(193)$ & & $16,369(402)$ & & $2,217(56)$ & \\
\hline Proportional hazards & 0.91 & & 0.94 & & 0.94 & & 0.89 & \\
\hline
\end{tabular}

S. e. represents standard errors. Additional definitions as in Table 3. Farmers identified with occupation at enlistment and rural populations with enlistments in counties with less than 2500 inhabitants, see Table 2.

*** The coefficient is significantly different from 1 at the $1 \%$ level.

** The coefficient is significantly different from 1 at the $5 \%$ level.

* The coefficient is significantly different from 1 at the $10 \%$ level.

Even if the diagnosis of tuberculosis at later stages is unproblematic, the diagnosis of additional diseases could introduce error-invariables to the estimation. For example, the widespread presence of the dysentery-diarrhea complex or the typho-malarial fevers suggests that those diseases were regularly confused. Since the misdiagnosis amounts only to a reclassification, the issues raised are not as problematic as the confusion between these diseases and tuberculosis itself.

There is no direct evidence to indicate the extent of the misdiagnosis in the Union Army data, but post-mortem examinations prove useful to evaluate the dimension of the problem. Post-mortem examinations, discussed in the Medical History of the Civil War (United States Army Surgeon General's Office, 1990, VI), frequently indicate tuberculosis in patients who died from pneumonia, diarrhea, dysentery, and malaria. The Medical History of the Civil War (United States Army Surgeon General's Office, 1990, VI, pp. 818) comments: "Men were taken sick with diarrhea and dysentery, continued fevers, measles, bronchitis, pneumonia and other diseases, and their cases were reported under these headings. Months afterwards they died or were discharged on account of tubercular disease of the lungs, although their names had never appeared in the list of those taken sick with consumption."

The evidence in the Medical History of the Civil War (United States Army Surgeon General's Office, 1990), however, is reassuring for our investigation because tuberculosis in other causes of death is present, but with the exception of diarrhea, in very limited amounts. The frequency of the cases is as follows: In 435 post-mortem examinations of deaths due to pneumonia, 30 (6.8\%) had tubercular disease. In 330 cases of fevers, 16 (4.8\%) had tubercles in the lungs, and tubercular deposits were observed in the lungs of 106 out of 667 post-mortem examinations of deaths coded as diarrhea and dysentery (15.8\%). The lungs of 147 malarial subjects were examined, but only in 11 cases (7.4\%) were there signs of tuberculosis. In the case of typhoid fever, 34 post-mortem examinations of the lungs were considered, but there was only one case (2.9\%) with pulmonary tubercle. ${ }^{19}$ These previous statistics suggest that under-diagnosis of tuberculosis was not a central concern. There is less evidence on the possibility of overdiagnosis but since the army disposed of tuberculosis by discharging soldiers, there were no incentives to over-diagnose the disease especially as the war progressed.

\subsection{Sample selection}

In addition to some of the concerns mentioned above, the analysis of tuberculosis in the Union Army raises additional questions associated with sample selection at several levels. On one hand, soldiers who enlisted in the army could be a "healthy" sample of the population as some were rejected after medical examinations at enlistment. On the other hand, as diagnosis of tuberculosis

\footnotetext{
19 Obviously, the presence of tubercular matter in patients whose causes of death were coded as other than tuberculosis is not necessarily an indication of misdiagnosis, especially with diarrhea. Due to the competing risk nature of mortality, tuberculosis could be present in those patients without actually leading to mortality. For example, examinations reveal cases in which diarrhea and dysentery contributed to the tubercular destruction of the lungs, although the records do not show the invasion of the intestinal membrane by the tubercular deposit, Medical History of the Civil War (United States Army Surgeon General's Office, 1990, VI, pp. 827).
} 
while in the army often lead to discharge (tuberculosis was the leading cause of discharge while in the army), it is also possible that recruits with a latent form of the disease were diagnosed only in the later stages of tuberculosis, suggesting that the sample contains an "unhealthy" part of a "healthy" population.

As the Civil War draws more than two million Northerners into the Union Army, the representativeness of the population by the Union Army sample is less problematic than the selection into diagnosis for soldiers already in the army. For example, the need for "warm bodies" may give companies a disincentive to discharge soldiers, especially taller recruits. That is, the protective effects of height in the previous tables may simple reflect a reduction in reported cases but not in actual ones. On a related note, we suggested above that the selective nature of diagnosis and discharge could in part be responsible for the protective effect of battles as they reduced the incentive or the possibility of seeking medical assistance. There is no direct way to examine how important selection into diagnosis was but it is interesting to notice that in a sample of recruits with no battle experience and no gun-shot wounds, the results of Table 3 remain unaffected (see the last column in Tables 4 and 5). That is, to the extent that selection into discharge or selection into seeking medical advice are related to the number of battles, the results suggest that selection plays no role in the results. We consider a separate strategy to examine selectivity aspects in mortality later on where we examine tuberculosis in a sample of veterans who visited doctors due to the promise of a pension and not necessarily due to the deterioration of their health which arguably leads to selectivity concerns during the war.

\subsection{Early-life influences}

Some of the previous estimates indicate that height had a protective effect for tuberculosis. These effects are not always robust but even if the estimates are taken to reflect a protective effect, it is important to recognize that height does not provide an accurate assessment of differences in diets but an overall assessment of how diets and disease varied early in life (Fogel, 2000). In particular, the protective effect of height may simply be the consequence of differences in early-life disease environments. This suggests that the disease component estimated in the previous tables is an underestimate of the overall impact of disease environments.

It is not possible to purge the disease component in height to offer a "pure" estimate of the role of the improvement in the diets on the mortality decline of tuberculosis but the influence of early-life conditions in height seems important. In fact, the analysis of Haines et al. (2003) suggests that the height of the soldiers of the Union Army varied mainly due to differentials in environmental conditions and somewhat less importantly with diets. This aspect is especially problematic for the presence of tuberculosis in early-life as it will lead to reverse causation (although as we noted before, this problem is more severe in the sample of soldiers unfit for service). In addition to the proxies for disease environments used in previous tables, we consider three ways to further the discussion about early diagnosis of tuberculosis. First, we recognize that the influence of height provides an upper bound for the "pure" contribution of diets to the mortality decline. Later on, we present these estimates in more detail. Second, we examine specific sub-populations that experienced different environmental conditions growing up including populations where TB was less common. These sub-populations include farmers and rural residents. Finally, we consider an analysis of TB mortality and control for weight, height, and for conditions during the war as a way to examine past disease loads. For instance, since we have information about the diagnosis of TB during the war, this variable is no longer unobserved in the veteran's sample.

Table 7 estimates the influence of nutritional status variables and infectious disease experience for farmers and non-farmers as well as for rural and non-rural populations. As we noted previously, tuberculosis was less common in rural areas, and as a result, the potential for early TB exposure is smaller for farmers than for urban populations. The results indicate that there is very little difference with the results in Table 3 and very little difference across sub-populations but the estimates of height lose statistical significance. For instance, the protective effect of height in soldiers who enlisted in non-rural counties (counties with more than

Table 8

Cox proportional hazard model for mortality due to tuberculosis.

\begin{tabular}{|c|c|c|c|c|c|c|c|c|}
\hline & \multicolumn{6}{|l|}{ Post-1890 } & \multicolumn{2}{|l|}{ Pre-1890 } \\
\hline & Hazard ratio & S. e. & Hazard ratio & S. e. & Hazard ratio & S. e. & Hazard ratio & S. e. \\
\hline \multicolumn{9}{|l|}{ A. Nutritional status } \\
\hline Wartime TB diagnosis & $3.741^{* *}$ & 0.591 & $3.344^{* *}$ & 0.593 & $3.306^{* *}$ & 0.593 & $3.217^{* * *}$ & 0.282 \\
\hline Age & 0.993 & 0.015 & 0.987 & 0.017 & 0.986 & 0.018 & 1.009 & 0.009 \\
\hline Height & 0.440 & 1.794 & $0.031^{*}$ & 1.989 & 11.010 & 2.071 & 2.361 & 1.315 \\
\hline Weight & - & - & - & - & $0.923^{* * *}$ & 0.017 & - & - \\
\hline BMI & - & - & $0.803^{* * *}$ & 0.049 & - & - & $0.816^{* * *}$ & 0.025 \\
\hline$\chi^{2}$ for likelihood ratio & $3.87^{* *}$ & & 27.10 & & 29.85 & & 69.23 & \\
\hline Observations (events) & $4694(72)$ & & $4133(67)$ & & $4133(67)$ & & $4838(141)$ & \\
\hline Proportional hazards & 0.73 & & 0.50 & & 0.97 & & 0.26 & \\
\hline
\end{tabular}

Days free from TB are measured from pension enrollment. S. e. represents standard errors. Mortality from tuberculosis is an event. Individuals who died from a cause of death other than TB are treated as censored. Wartime diagnosis refers to diagnosis of TB during the Civil War. Age is the age at pension enrollment. $\mathrm{BMI}=$ weight $/(\text { height })^{2}$. Pre-1890 sample excludes deaths during the Civil War. Additional definitions as in Table 3.

*** The coefficient is significantly different from 1 at the $1 \%$ level.

** The coefficient is significantly different from 1 at the $5 \%$ level.

* The coefficient is significantly different from 1 at the $10 \%$ level. 
2500 inhabitants) is larger than in any of the other groups but it is not statistically different from one. In the other columns, the coefficient of height still indicates some protection but the significance is lower. As with previous tables, this seems to be the consequence of reduced sample sizes.

Table 7 also implies that the adverse effects of waterborne diseases such as diarrhea and dysentery are fairly uniform across the population and quite robust. This is also in line with our previous estimates. Thus, to the extent that exposure to disease in early life differed between farmers and non-farmers (or rural and non-rural inhabitants), the results of Table 7 suggest that early-life conditions had only limited influence on the diagnosis of tuberculosis or on the influence of waterborne diseases in tuberculosis.

\section{Tuberculosis mortality in Union Army veterans}

The purpose of this section of the paper is to extend the analysis to consider tuberculosis mortality for veterans of the Union Army. While the analysis of discharge and diagnosis presented above provides useful insights, a shortcoming of the previous estimates is that regiments during the Civil War were relieved of tuberculosis by discharge and not by death. Other concerns with the previous estimates will also be less present here.

To study mortality, we consider veterans of the Union Army and rely on legal changes in the assignment of pensions for service in the army. In particular, beginning in 1890, pensions were granted on the grounds of service in the Union Army and not by wounds received during the war, as it was the case before 1890. Associated with these pension applications are detailed physical examinations, completed by physicians, who certify the veterans' health status. Measures of weight and specific causes of death are also available so we can employ additional controls not available before. For instance, we can study individuals who have already been diagnosed with tuberculosis (either during the war or after) and study the effect of nutritional variables, occupation, and disease loads on their mortality rates.

There are some additional important advantages from using mortality statistics from after the war. First, tuberculosis is a chronic disease and no treatment was available before the 1940s. Since we have already established which soldiers were diagnosed with tuberculosis during the Civil War, we can in part overcome the problem of not having a date of acquisition of the disease. Second, after 1890 pensions were given by service so we can study a population with less direct effects of the war. This will minimize the selection effects that arose while the soldiers were in the army. Finally, measurement of TB improved in the early 1890s as tuberculin tests first became available for the diagnosis of tuberculosis, (see Olmstead and Rhode, 2004, Table 1). This

Table 9

Cox proportional hazard model for tuberculosis mortality.

\begin{tabular}{|c|c|c|c|c|c|c|}
\hline & Hazard ratio & S. e. & Hazard ratio & S. e. & Hazard ratio & S. e. \\
\hline \multicolumn{7}{|l|}{ A. Nutritional status } \\
\hline Height & $0.039^{*}$ & 2.005 & $0.039^{*}$ & 1.974 & 0.056 & 2.005 \\
\hline BMI & $0.803^{* * *}$ & 0.049 & $0.815^{* * *}$ & 0.049 & $0.818^{* * *}$ & 0.049 \\
\hline Age & 0.983 & 0.017 & 0.985 & 0.017 & 0.983 & 0.017 \\
\hline \multicolumn{7}{|c|}{ B. Infectious disease experience } \\
\hline \multicolumn{7}{|c|}{ Tuberculosis diagnosis } \\
\hline Wartime diagnosis & $3.118^{* * *}$ & 0.601 & 1.813 & 0.643 & 2.336 & 0.644 \\
\hline Post-war diagnosis & - & - & $10.243^{* * *}$ & 0.524 & $13.122^{* * *}$ & 0.515 \\
\hline \multicolumn{7}{|l|}{ Wartime disease experience } \\
\hline Diarrhea and dysentery & - & - & - & - & 0.752 & 0.362 \\
\hline Fever & - & - & - & - & 0.787 & 0.3504 \\
\hline Measles & - & - & - & - & 0.263 & 1.069 \\
\hline Typhoid & - & - & - & - & 1.065 & 0.724 \\
\hline Bronchitis & - & - & - & - & 1.309 & 0.612 \\
\hline Pleuritis & - & - & - & - & 2.998 & 0.737 \\
\hline \multicolumn{7}{|l|}{ Post-war disease experience } \\
\hline Diarrhea & 0.604 & 0.430 & 0.653 & 0.431 & 0.713 & 0.438 \\
\hline Pneumonia & 2.393 & 1.055 & 1.893 & 1.029 & 1.638 & 1.049 \\
\hline Pleuritis & 2.672 & 0.763 & 2.080 & 0.745 & 1.717 & 0.760 \\
\hline \multicolumn{7}{|l|}{ E. Occupation } \\
\hline \multicolumn{7}{|l|}{ Occupation at enlistment } \\
\hline Farmer & - & - & - & - & 0.622 & 0.312 \\
\hline Professional & - & - & - & - & 0.486 & 0.518 \\
\hline Artisan & - & - & - & - & 0.622 & 0.388 \\
\hline \multicolumn{7}{|l|}{ Post-war occupation } \\
\hline Professional & $3.093^{*}$ & 0.471 & $3.198^{*}$ & 0.470 & $3.184^{*}$ & 0.480 \\
\hline Services & 1.497 & 0.596 & 1.516 & 0.597 & 1.576 & 0.604 \\
\hline$\chi^{2}$ for likelihood ratio & 35.90 & & 48.62 & & 59.01 & \\
\hline Observations (events) & $4130(67)$ & & $4130(67)$ & & $4116(67)$ & \\
\hline Proportional hazards & 0.09 & & 0.08 & & $4.08^{*}$ & \\
\hline
\end{tabular}

Additional definitions as in Table 7.

*** The coefficient is significantly different from 1 at the $1 \%$ level.

* The coefficient is significantly different from 1 at the $10 \%$ level. 
Percent contribution to tuberculosis diagnosis and discharge.

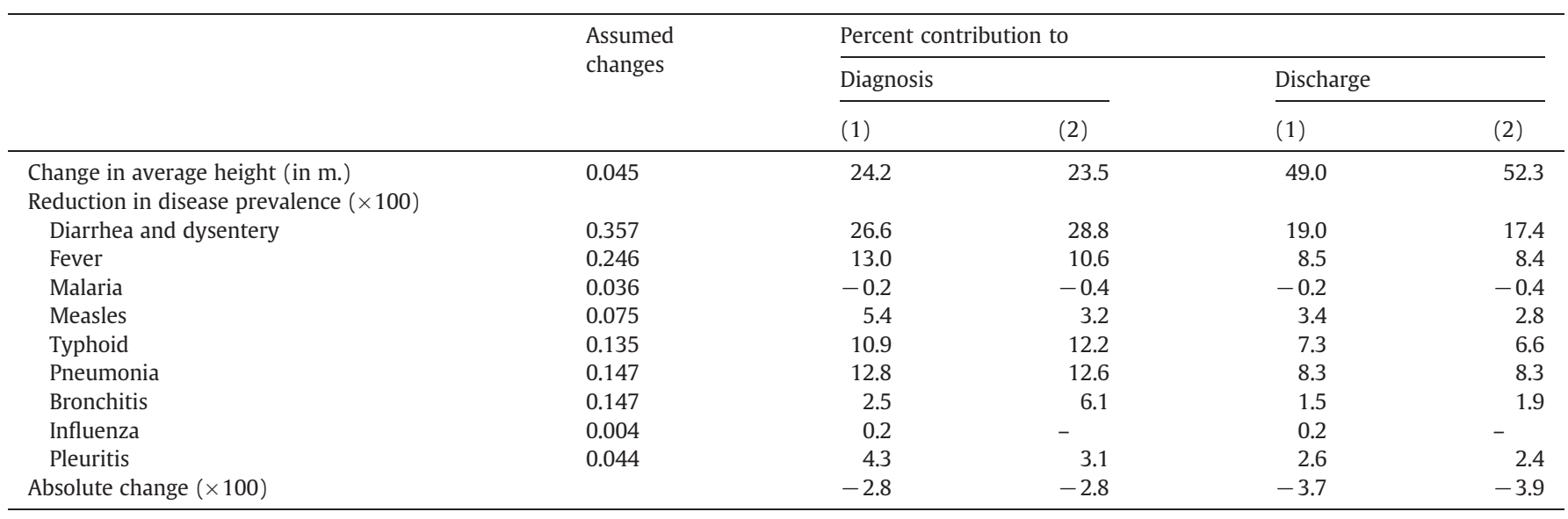

Estimates in column (1) are based on the hazards of Table 3. Column (2) is based on the last column in Tables 4 and 5, or for recruits with no battle experience. The significance of coefficients is in the original tables. Changes in height are assumed as the difference between average heights in the Union Army and in the NHANES for males aged between 25 and 45. Changes in disease prevalence correspond to the eradication of diseases in the sample prior to diagnosis or discharge.

increases the accuracy of the diagnosis of the disease.

We consider a Cox proportional hazard model as in Eq. (1) for the time duration between pension enrollment and mortality (mortality by causes other than tuberculosis is treated as censored). We consider two sub-samples, one with veterans who enrolled before 1890 and one with those who enrolled after. Initially, we control for the diagnosis of tuberculosis in the Civil War, the age of the veteran, and height. Since the number of events is reduced (to less than 100), precision is also reduced; however, in both sub-samples, diagnosis during the war increases the risk of tuberculosis mortality after the war, see Table 8 . Table 8 also adds controls for BMI and height in both sub-samples.

Table 8 shows that, as expected, diagnosis of tuberculosis during the war increases the mortality risk for TB. The effect is of roughly the same magnitude in recruits who received pensions as a consequence of war injuries and for recruits who received pensions after 1890. (This implies that once diagnosed, case fatality rates vary little with war-related variables.) The effect of BMI is also equivalent in both sub-samples. If height is considered alone, its effects are in the same order of magnitude as before (Tables 3-6) because the hazard rate is 0.44 , but height is no longer statistically different from 1 . In fact, it is not possible to reject the joint hypothesis that the coefficients on diagnosis and height are equal to 1 in the first column of Table 8. Once BMI measures are taken into account, height has an independent protective effect in post-1890 veterans. This effect is statistically different from 1 but only at the $10 \%$ level. This coefficient suggests that in addition to linear effects of height, there are non-linear effects of height on mortality that operate mainly through BMI. ${ }^{20}$

We have computed BMI using weight measures at the first medical examination that granted a pension. Thus, it is possible to argue that the effect of BMI is due to reverse causation by previous disease insults (war effects seem unlikely since the sub-samples already control for war-related injuries and provide no statistical difference between the estimates of BMI).

Table 9 shows that the effects of BMI are not affected by the inclusion of conditions acquired while in service or similar conditions diagnosed after pension enrollment. Once controls for past disease experience and occupation are implemented, the protective effects of having a high body mass index remain statistically significant. Table 9 also implements controls for previous diagnosis of TB in the veterans. As in the previous tables, height remains statistically different from 1 when BMI is included in most specifications, but when controls for past disease experiences and diagnosis for tuberculosis are included, height is no longer statistically different from 1 . The effect of BMI, on the other hand, fails to disappear even after the numerous controls are included. Since we have explicitly controlled for disease experiences during the war and after pension enrollment, the higher risk associated with low BMI seems unrelated to previous disease experience.

As before, we implement a series of robustness checks. ${ }^{21}$ We use a sample of veterans who received pensions before 1890 , and we have restricted the sample to veterans who died after 1896, 1901, and 1911 but who had received pensions since 1890 . In those sub-samples, BMI still has a positive effect on survival (the effect actually increases for veterans who died after 1901). Stratification

\footnotetext{
20 Notice also that a disaggregate analysis that includes only weight and height shows that the protective effect of BMI operates mainly through weight. For example, notice that the inclusion of weight as a separate covariate yields a hazard for height of about 11 although not statistically significant. The hazard of height in the regression that includes BMI (which is computed using the square of height) is 0.031 . This implies that weight and height are strongly correlated and so the inclusion of non-linear terms for height in the absence of controls for weight is uninformative. If weight had no separate role in tuberculosis, the inclusion of the square of height would be informative.

21 In Table 8, the proportionality hypothesis of the Cox model is rejected in the last column. An analysis of residuals reveals that this is due to the significant effect of the interaction between post-war diagnosis of tuberculosis and time. Including such an interaction allows for non-proportionality, but even in such case, the results regarding BMI remain unaffected. Most of the difference is given in a much higher effect of tuberculosis diagnosis. We have also stratified the sample according to the diagnosis of TB. The hazard for BMI is 0.821 , still statistically different from 1 . Under the stratification, the non-proportional problem is also absent.
} 
by late TB diagnosis also displays the protective effects of BMI, and the inclusion of additional variables (population size at enlistment and war-related variables) makes no difference to the effects of BMI. Medical reports for veterans also contained measures of the severity of the different diseases, and we use episodes of severe diarrhea instead of any episode in the regression. However, the effect of disease loads is not statistically different from 1 once diagnosis of TB is included. As in Table 9, height is only marginally significant in most specifications.

\section{Contributions to the decline}

This section brings the previous estimates to bear on the contribution of different factors for the mortality decline of tuberculosis. To highlight the importance of TB, notice than in 1900, the "all-causes" mortality rate in the U.S. population was 1719 (per 100,000), and the mortality rate from all forms of tuberculosis was 194. In 1940, the all-causes mortality rate was 1076 while the mortality rate from tuberculosis was 46 (CDC Center for Disease Control, 2005). While overall death rates declined by 40\%, mortality rates from tuberculosis experienced almost an 80\% decline between 1900 and 1940 .

To evaluate the contribution of different factors to the decline in the prevalence of tuberculosis we estimate the change in risk rates if the average Union Army soldier had the average height of the current U.S. male population and if such a recruit never had suffered from diarrhea or other conditions prior to tuberculosis. That is, we compare the risk of tuberculosis in a modern representative individual, tall and healthy, with a representative Union Army soldier.

We specifically consider the following scenario described in Table 9 . We assume that height increases by $4.5 \mathrm{~cm}$ from $1.71 \mathrm{~m}$ (in Table 2) to about 1.76, which is the average height of males with ages between 25 and 45 in the NHANES survey. We also assume that infectious diseases other than tuberculosis are eradicated. ${ }^{22}$ The estimates in Tables 3-6 define the percentage change in the hazard rate associated with a unit change in the predictor so a log-transformation defines the response to other changes. For example, the hazard rate for height in Table 3 is 0.859 so its coefficient is $\ln (0.859)=-0.15 .^{23}$ Since height changed by $4.5 \mathrm{~cm}$, the absolute effect of height on the log-hazard is given by $-0.15 \times 0.045=-0.007$. Similarly, we can compute the effect of disease eradication and add all the effects to obtain a total predicted absolute change of -0.028 (the last line in Table 9). Hence, of the predicted 0.028 change, height contributes in about $0.007 / 0.028$ or $24 \%$ as Table 10 reports. ${ }^{24}$

Table 10 shows that the contribution of increased heights ranges from one-fourth to one-half of the predicted decline. Since we acknowledged a potential bias in the analysis of discharge, as height could have an independent value while in the army, our preferred estimates are based on the analysis of diagnosis. There, the contribution of height is estimated to be $25 \%$. The effects associated with public health changes given in terms of the prevalence of diarrhea, perhaps the main reason for the bias in McKeown (1977), account for roughly the same fraction as changes in height. If the decomposition provided in Table 10 is taken to reflect specific disease influences, our findings confirm the important effect that waterborne and respiratory conditions have on explaining the decline in the prevalence of tuberculosis (Preston and Van de Walle, 1978).

We have, perhaps correctly, assumed that differences in height were not only due to differences in diets. The estimates that served to produce Table 10 include a control for early life conditions in the county of enlistment and measures of population size so we tried the best possible way to minimize the "disease" aspect of heights. As the population size of the county of enlistment is an imperfect control, it is possible that changes in disease insults have a much larger effect in lowering tuberculosis prevalence as some influences will be seen in increases in height while others in the protection against TB in mid-life. In other words, while there is no ambiguity with respect to the interpretation of changes in disease loads, the gains associated with differences in height can be taken as improvements in the diet or as additional improvements in the disease environment during growing years. A separation, as the one suggested by McKeown (1977), is clearly not possible. The evidence in Table 10 thus provides an upper bound for the role of "pure" changes in diets and a lower bound for the role of disease environments in the mortality decline of tuberculosis.

In Table 10, we considered only variations in nutritional status and disease experience and ignored influences specific to the war, occupational changes, and variations in the distribution of the population. The risk of diagnosis is higher for people living in small towns, so Table 9 would underestimate the effect of all the other variables in the current decline. Also, as we noted, the occupational structure failed to play a significant role in the diagnosis or discharge of tuberculosis. Professionals, however, had an elevated mortality risk from tuberculosis in Table 9.

\footnotetext{
22 In contrast to Table 2, the average prevalence of the conditions listed in Table 9 under assumed changes makes reference to the disease experience prior to tuberculosis; hence, they are lower than the unrestricted average in Table 2. That is, our predicted measures were constructed for cases in which the diseases pre-dated the diagnosis and discharge of tuberculosis.

${ }^{23}$ A referee pointed out that the response to different changes in the covariates, the estimated $\beta$ s, could change due to technological or physiological changes in the way the different factors affect the risk of tuberculosis. This hypothesis was considered by Fogel and Costa (1997). Our results can then be seen as an approximation in which the additional physiological effects are ignored.

24 Assuming that the risk scores $\beta$ are constant, based on Eq. (1), we can describe the decomposition as:
}

$$
\ln h^{\text {Modern }}(t \mid \mathbf{x} \beta)-\ln h^{\text {Union Army }}(t \mid \mathbf{x} \beta)=\left(\mathbf{x}^{\text {Modern }}-\mathbf{x}^{\text {Union Army }}\right) \beta,
$$

with $\mathbf{x}^{\text {Modern }}-\mathbf{x}^{\text {Union Army }}$ as the assumed changes. The last line in Table 9 gives the total difference of the log-hazard, $\ln \left[h^{\text {Modern }}(t \mid \mathbf{x} \beta) / h^{\text {Union }}\right.$ Army $\left.(t \mid \mathbf{x} \beta)\right]$, so the overall variation is given by the exponential of the difference. Note, for example, that the overall variation in the hazard is rather small. Since exp $\{-0.028\}=$ 0.97, the fraction of the baseline hazard reduced by the interventions is only $3 \%$ (and at most $5 \%$ for discharge) so other influences in the absolute risk are still unaccounted for. For that reason we need to note that our numbers make reference to relative changes only. 
The estimates in the previous section also serve to examine mortality rates. In the NHANES survey (all waves), the average BMI of males aged 25-45 is 26.62 while in the Union Army sample the average BMI is 23.33 (see Table 2). The hazard of BMI on tuberculosis mortality is 0.818 in Table 8 so the coefficient is -0.20 . If the difference between the two data points is used to predict differentials in mortality, the estimated gain is $-0.20 \times 3.29=-0.66$. In contrast to changes in diagnosis, the absolute predicted change in mortality is as large as $\exp \{-0.66\}=0.51$. That is, the absolute risk of mortality declines in about $50 \%$ due to observed improvements in BMI. This number is consistent with the estimates provided in Table 10. Thus, the evidence present so far suggests that the observed gains in weight and height account for an important part of the mortality decline from tuberculosis but that the influence of improvements in disease environments is more important (or at least as important) and these changes in BMI and height.

We have considered the potential effect of disease loads and nutritional change in tuberculosis, but it is important to note that the aspects studied constitute only a partial list of potential explanations. As Olmstead and Rhode (2004) have shown, one of the most important achievements in tuberculosis control was the official inspection of cattle and the eradication of bovine tuberculosis in the United States. Campaigns that improved the quality of the milk supply also contributed to the reduction of tuberculosis and other water and foodborne diseases. Additional measures, such as the reporting and registration of tuberculosis cases followed by isolation, as well as improved treatment of tubercular patients in hospitals and educational campaigns that disseminated information about the contagious nature of the disease were also a response to the knowledge that arose from the development of the germ theory of disease (see, for example, Bryder, 1988; Barnes, 1995; Lowell, 1969).

It is unquestionable that the previous public health initiatives had an important effect on the course of tuberculosis, but their contribution, with the exception of the eradication of bovine tuberculosis studied by Olmstead and Rhode (2004), is difficult to evaluate since tuberculosis mortality began its decline before the advent of the germ theory of disease and because the trend in mortality up to the late 1940s, when streptomycin became available, was steady (see Figs. 1 and 2). ${ }^{25}$

\section{Conclusions}

This paper examined the medical histories of a sample of 25,000 Union Army soldiers and veterans to study the determinants of diagnosis, discharge, and mortality from tuberculosis in past populations. Our results confirmed the importance of a synergistic relationship between waterborne diseases and tuberculosis as the diagnosis of tuberculosis was far more common in soldiers with a prior history of diseases such as diarrhea and typhoid. Airborne diseases such as pneumonia, measles, and bronchitis also raised the risk of tuberculosis. We also found that height was associated with a reduced risk of diagnosis and discharge from tuberculosis and that a higher body mass index (BMI) reduced the mortality risk from tuberculosis. Certain occupations, due to the exposure to dust and fumes, often increase the risk of developing tuberculosis, but in our sample occupation has no predictive power for tuberculosis maybe because the conditions of the war were equally harsh on the population.

In the paper, we also considered mortality rates due to tuberculosis for a sample of veterans who received pensions after 1890 by factors unrelated to their injuries during the war. In the case of mortality, height still plays a protective role but often not with statistically significant effects. BMI, on the other hand, remains robust to the inclusion of disease loads during the war and after enrollment, early life conditions, and occupation during the war and after. Unfortunately, the sample is too small to attempt additional controls related to wealth information in the Federal Censuses.

Since the decline in mortality from tuberculosis accounts for an important fraction of the overall mortality decline, it is not surprising that multiple hypotheses have been proposed to explain why tuberculosis mortality declined. Based on the evidence presented throughout the paper, we argue that between one-quarter to one-half of the predictable decline in tuberculosis could be associated to the modern increase in final heights and BMI. Since height and BMI reflect past and current influences of disease and diets, a complete separation of both effects is unattainable, see, for example, Preston and Van de Walle (1978) and Fogel (1997). Still, the previous estimates provide an upper bound for the role of "pure" nutritional influences in the mortality decline from tuberculosis. Since this upper bound is between one-quarter and one-half of the decline, our findings suggest that the elimination of waterborne diseases such as diarrhea was among the most important influences in the mortality decline of tuberculosis. The influence of nutritional variables, however, cannot be taken as insignificant.

\section{Acknowledgments}

This paper is based on my dissertation research. I would like to thank the Editor and two anonymous referees for important suggestions. I also thank Dora Costa, Charles Holmes, and Chulhee Lee for comments on earlier versions of the paper. I benefited from comments and discussions with Todd Bridges, Robert Fogel, Max Henderson, Susan Jones, Ethan Lieber, Claudia Linares, Andrew Noymer, and seminar participants at the NBER Early Indicators of Later Work Levels, Disease and Death and Cohort Studies, and the Center for Population Economics, University of Chicago.

This study was supported by a grant from the National Institute on Aging, P01 AG10120.

\footnotetext{
25 Olmstead and Rhode (2004) considered moderate estimates of the role of the bovine form of tuberculosis but showed that the benefits in the livestock sector and, more importantly, in human health were several times larger than the cost imposed by the eradication.
} 


\section{References}

Barker, D.J.P., 1994. Mothers, Babies and Disease in Later Life. BMJ Publishing Group.

Barnes, D., 1995. The Making of a Social Disease. University of California Press.

Bengtsson, T., Lindström, M., 2000. Childhood misery and disease in later life: the effects of mortality in old age by hazards experienced in early life, Southern Sweden, 1760-1894. Population Studies 54, 263-277.

Bhatti, N., Law, M.R., Morris, J.K., Halliday, R., More-Gillon, J., 1995. Increasing incidence of tuberculosis in England and Wales: a study of the likely causes. British Medical Journal 310, 967-969.

Bryder, L., 1988. Below the Magic Mountain. A Social History of Tuberculosis in Twentieth-Century Britain. Claredon Press.

Caselli, G., 1991. Health transition and cause-specific mortality. In: Schofield, R., Reher, D., Bideau, A. (Eds.), The Decline of Mortality in Europe. Clarendon Press, Oxford, pp. 97-117.

Center for Disease Control, 2005. Vital Statistics in the United States, 1900-1940. available at http://www.cdc.gov/nchs/products/pubs/pubd/vsus/vsus.htm.

Chandra, R., 1996. Nutrition, immunity and infection: from basic knowledge of dietary manipulation of immune responses to practical application of ameliorating suffering and improving survival. Procedures of the National Academy of Sciences USA 93 (25), 14304-14307.

Comstock, G., Livesay, V., Woolpert, S., 1974. The prognosis of a positive tuberculin reaction in childhood adolescence. American Journal of Epidemiology 99, $131-138$.

Comstock, G., Cauthen, G., 1993. Epidemiology of tuberculosis. In: Reichman, L., Hershfield, S. (Eds.), Tuberculosis. A Comprehensive International Approach. Marcel Dekker Inc., pp. 23-48.

Costa, D.L., 2003. Understanding mid-life and older age mortality declines: evidence from Union Army veterans. Journal of Econometrics $112,175-192$.

Drolet, G., 1938. Present trend of case fatality rates in tuberculosis. American Review of Tuberculosis 37, 125-151.

Dubos, R., Dubos, J., 1953. The White Plage: Tuberculosis. Man and Society, London.

Dutt, A., Stead, W., 1999. Epidemiology and host factors. In: Schlssberg, D. (Ed.), Tuberculosis. W.B. Saunders Company, pp. 3-16.

Elo, I., Preston, S., 1992. Effects of early-life conditions on adult mortality: a review. Population Index 58, 186-212.

Felton, C., Ford, J., 1993. Tuberculosis in the inner city. In: Reichman, L., Hershfield, S. (Eds.), Tuberculosis. A Comprehensive International Approach. Marcel Dekker Inc., pp. 483-504.

Ferebee, S.H., Mount, F.W., Murray, F.J., Livesay, V.T., 1963. A controlled trial of isoniazid prophylaxis in mental institutions. American Review of Respiratory Diseases 88, 161-175.

Ferrie, J.P., 2001. The poor and the dead: socioeconomic status and mortality in the US, 1850-1860. NBER Working Paper No. H0135.

Ferrie, J.P., Troesken, W., 2005. Death and the city: Chicago's mortality transition, 1850-1925. NBER Working Paper No. 11427.

Fogel, R.W., 1997. New findings on secular trends in population and mortality. In: Rosenzweig, M., Stark, O. (Eds.), Handbook of Population and Family Economics. North Holland, pp. 434-481.

Fogel, R.W., 2000. Public use tape on the aging of veterans of the Union Army: military, pension and medical records, 1860-1940. Center for Population Economics. Available from www.cpe.uchicago.edu.

Fogel, R.W., Costa, D.L., 1997. A theory of technophysio evolution, with some implications for forecasting population, health care costs, and pension costs. Demography 34, 49-66.

Grigg, E., 1958. The arcana of tuberculosis. With a brief epidemiologic history of the disease in the USA. Part III. American Review of Tuberculosis and Pulmonary Disease 78, 426-453.

Haines, M.R., Craig, L.A., Weiss, T., 2003. The short and the dead: nutrition, mortality, and the "Antebellum Puzzle" in the United States. Journal of Economic History $63,385-415$

Hawker, J., Bakshi, S., Ali, S., Farrington, C., 1999. Ecological analysis of ethnic differences in relation between tuberculosis and poverty. British Medical Journal 319 (7216), 1031-1034.

Johnson, J., 1993. Tuberculosis. In: Kiple, K. (Ed.), Cambridge World History of Human Disease. Cambridge University Press.

Lawless, J.F., 2003. Statistical Models and Methods for Lifetime Data. Wiley Interscience.

Lee, C., 1997. Socioeconomic background, disease, and mortality among Union Army recruits: implications for economic and demographic history. Explorations in Economic History 34, 27-55.

Lowell, A.M., 1969. Tuberculosis Morbidiy and Mortality and Its Control. Harvard University Press.

Mangtani, P., Jolley, D., Watson, J., Rodrigues, L., 1995. Socioeconomic deprivation and notification rates for tuberculosis in London during 1982-1991. British Medical Journal 310, 963-966.

McKeown, T., 1977. The Modern Rise of Population. Edward Arnold.

Mercer, A., 1990. Disease Mortality and Population in Transition. Leicester University Press.

Meyer, S., 1949. Statistical Investigations of the Relationship of Tuberculosis Morbidity and Mortality to Infection. Munksgaards Forlag Copenhagen.

Noymer, A., Garenne, M., 2004. The 1918 influenza epidemic's effects on sex differentials in mortality in the United States. Population and Development Review 26, $565-581$.

Olmstead, A., Rhode, P., 2004. An impossible undertaking: the eradication of bovine tuberculosis in the United States. Journal of Economic History 64, 1-39.

Preston, S., Van de Walle, E., 1978. Urban French mortality in the nineteenth century. Population Studies 32, 275-297.

United States Provost Marshall General, 1875. Medical Statistics of the Provost Marshall General's Bureau. Executive Document Washington Printing Office.

Puffer, P.R., Griffith, G.W., 1967. Patterns of Urban Mortality. Pan American Health Association.

Puranen, B., 1991. Tuberculosis and the decline of mortality in Sweden. In: Schofield, R., Reher, D., Bideau, A. (Eds.), The Decline of Mortality in Europe. Clarendon Press, Oxford, pp. 97-117.

Raloff, J., 1996. Protein deficiency abets tuberculosis. Science News 150 (24), 374.

Raviglione, M., Snider, D., Kochi, A., 1995. A global epidemiology of tuberculosis. Morbidity and mortality of a worldwide epidemic. Journal of the American Medical Association 273, 220-226.

Sagan, L., 1987. The health of nations. True Causes of Sickness and Well-Being. Basic Books.

Scrimshaw, N., SanGiovanni, J., 1997. Synergism of nutrition, infection and immunity: an overview. The American Journal of Clinical Nutrition 66, S464-S477.

Spence, D.P.S., Hotchkiss, J., Williams, C.S.D., Davis, P.D.O., 1993. Tuberculosis and poverty. British Medical Journal 307, $759-761$.

Tocque, K., Bellis, M.A., Beeching, N.J., Syed, Q., Remington, T., Davis, P.D.O., 2001. A case-control study of lifestyle risk factors associated with tuberculosis in Liverpool, North-West England. The European Respiratory Journal 18, 959-964.

Tverdal, A., 1988. Height, weight, and incidence of tuberculosis. Bulletin of the International Union against Tuberculosis and Lung Disease 63 (2), 16-18.

United States Army Surgeon General's Office, 1990. The Medical and Surgical History of the Civil War. Broadfoot Publishing Company, Wilmington, NC.

Waaler, H., 1984. Height, weight and mortality: the Norwegian experience. Acta Medica Scandinavia 679, 1-56 (Suppl.).

Wolff, G., 1940. Tuberculosis mortality and industrialization. American Review of Tuberculosis 42, 1-26.

Woods, R., 2000. The Demography of Victorian England and Wales. Cambridge University Press.

Woods, R., Shelton, N., 1997. An Atlas of Victorian Mortality. Liverpool University Press, Liverpool. 